\title{
Futuros en contrapunto: proyección, predicción y deseo en maya yucateco
}

Futures in counterpoint: projection, prediction and desire in Yucatec Maya

Futurs en contrepoint : projection, prédiction et désir en maya yucatèque

\section{Valentina Vapnarsky}

\section{(2) OpenEdition}

\section{Journals}

\section{Edición electrónica}

URL: http://journals.openedition.org/jsa/15387

DOI: $10.4000 /$ jsa. 15387

ISSN: 1957-7842

Editor

Société des américanistes

Referencia electrónica

Valentina Vapnarsky, « Futuros en contrapunto: proyección, predicción y deseo en maya yucateco », Journal de la société des américanistes [En línea], Maya times | 2017, Publicado el 31 diciembre 2017 consultado el 19 abril 2019. URL : http://journals.openedition.org/jsa/15387 ; DOI : 10.4000/jsa.15387 


\title{
Futuros en contrapunto: proyección, predicción y deseo en maya yucateco
}

\author{
Valentina VAPNARSKY*
}

El articulo trata de los modos de aprensión del futuro y de proyección en el provenir entre los mayas yucatecos, a partir de un análisis de la expresión de enunciados prospectivos, contemplados en el espesor etnográfico de las situaciones de comunicación. El maya yucateco distingue dos órdenes mayores de futuro: un futuro relativo a los acontecimientos predeterminados, fuera del control de la acción humana, conocido pero disociado de la acción presente (bíin), y un futuro (o un por-venir) en continuidad con las potencialidades de la esfera de la enunciación y del contemporáneo. Éste se expresa por un amplio conjunto de otros prospectivos: inminente e ingresivo mika 'aj, deóntico y proyectivo yan, desiderativo tak, asertivo je'el, etc. Se trata de dilucidar como, en las actividades y las circunstancias del mas o menos cotidiano, los interlocutores mayas contrastan formas de instigación y de control sobre la acción, de compromiso y no compromiso, de causalidad necesaria o intencionada. El objetivo in fine consiste en explicitar los modos tipificados de posicionamiento frente al porvenir, y la articulación entre los marcos temporales, intersubjetivos, epistémicos y agentivos. [Pababras claves: futuro, prospectivo, profecía, epistémico, intersubjetivo, marco temporal.]

Futures in counterpoint: projection, prediction and desire in Yucatec Maya. This paper studies the ways in which the contemporary Yucatec Maya apprehend the future and project themselves into it. It is based on an analysis of linguistic choices in the expression of prospective utterances, which are examined ethnographically in the midst of communicative situations. Yucatec Maya distinguishes between two major perspectives of the future: a future of predetermined events beyond the control of human action, which are known but are disconnected from present action (biin), and a future in continuity with the potentialities of the speech event and the contemporary world, expressed by a broad range of other prospective forms: imminent and ingressive mika'aj, deontic and projective yan, desiderative tak, assertive je'el, etc. Through a situated analysis of the use of these prospective forms, this paper attempts to elucidate how Maya interlocutors, in more or less ordinary everyday activities and circumstances, contrast forms of instigation and control, engagement and disengagement, as well as necessary or intentional causality. The

* CNRS, EREA-Laboratoire d'ethnologie et de sociologie comparative, 21 allée de l’Université, 92023 Nanterre Cedex [valentina.vapnarsky@cnrs.fr]. 
ultimate aim is to reveal Maya typified stances in relation to the future, and show how these connect with temporal, intersubjective, epistemic and agentive frames. [Key words: future, prospective, prophecy, epistemic, intersubjective, temporal frame.]

Futurs en contrepoint : projection, prédiction et désir en maya yucatèque. Cet article traite des modes d'appréhension du futur et de projection dans l'avenir chez les Mayas Yucatèques contemporains. Il part de l'analyse de choix linguistiques dans l'expression d'énoncés prospectifs, envisagés dans l'épaisseur ethnographique des situations de communication. Le maya yucatèque distingue deux ordres majeurs de futur : un futur des événements prédéterminés, hors du contrôle de l'action humaine, connu mais disjoint de l'action présente (bíin), et un futur (ou un à-venir) en continuité avec les potentialités de la sphère de l'énonciation et du contemporain, exprimé par un large ensemble d'autres prospectifs : imminent et ingressif mika'aj, déontique et projectif yan, désidératif tak, assertif je'el, etc. Il s'agit d'élucider comment les interlocuteurs mayas, pris dans les activités et les circonstances du plus ou moins quotidien, contrastent des formes d'instigation et d'emprise sur l'action, d'engagement et de désengagement, de causalité nécessaire ou intentionnée. On entend ainsi in fine mettre au jour des modes typifiés de positionnement face à l'avenir, et comment s'y articulent des cadres temporels, intersubjectifs, épistémiques et agentifs. [Mots-clés : futur, prospectif, prophétie, épistémique, intersubjectif, cadre temporel.]

\author{
la memoria custodisce il silenzio \\ ricordo del futuro la promessa \\ quale promessa? questa che ora arrivi \\ a sfiorare col lembo della voce \\ e ti sfugge come il vento accarezza \\ il buio nella voce il ricordo \\ in penombra un ricordo del futuro. \\ Italo Calvino, Un re in ascolto
}

\title{
Pasando el futuro pasado
}

Que el futuro se encuentre en el pasado parece ser, sin duda, uno de los vectores principales de la temporalidad maya para muchos especialistas de las culturas mesoamericanas prehispánicas, coloniales y más modernas. Expresiones memorables fueron propuestas para evocarlo: The Ancient Future of Mayas; Recordando el futuro, anticipando el pasado; La construcción del futuro pasado (Edmonson 1982; Farriss 1987; Okoshi 2015). Y varios argumentos fueron enunciados que sostienen dicha idea, en los ámbitos de la epigrafía y la arqueología, la historia, la etnología y la lingüística: las concepciones cíclicas del tiempo y de la historia que inducen a buscar el porvenir hacia atrás; la recurrencia de los acontecimientos históricos que permite la previsibilidad (de la Garza 1975; Bricker 1981a); las profecías que hacen del futuro un horizonte ya conocido; la repetición de los esquemas de transformación que subsumen 
acciones políticas individuales bajo acontecimientos cíclicos (Gossen 1974, 1999; Bergeret 2017, en esta publicación); los encuentros oníricos con los antepasados que dictan decisiones; las copias de los documentos que escriben el porvenir con lo acontecido (Okoshi 2015); las lenguas que ponen el futuro detrás (Schumann 1981); los gestos que lo figuran como un retorno circular (Le Guen 2012; Le Guen y Pool Balam 2012).

Si bien los aspectos mencionados tienen fundamentos certeros, consideramos imprescindible recalcar, no obstante, que dan a ver una cara claramente limitada de las aprehensiones del futuro ${ }^{1}$. La absorción del futuro por el pasado evocada, 0 invocada, en los trabajos previos no agota, ni mucho menos, la gran diversidad de modos de relacionarse con el porvenir que se expresan y se viven en las sociedades mayas en la actualidad, y que muy probablemente se vivieron en épocas anteriores, como ya lo destacaba Monod Becquelin (1995) en un artículo programático. El futuro que, en las concepciones mayas, se construye mediante una proyección normada del pasado, es un futuro que atañe más que todo a la historia colectiva, a tiempos construidos de forma reflexiva y trabajados por memorias compartidas. Sin embargo, paralelamente, varios otros tipos de posicionamientos frente al porvenir coexisten en los tiempos vividos, narrados y creados de ámbitos más íntimos y cotidianos, personales e interpersonales, o diferentemente colectivos. Futuros en contrapunto de la historia colectiva, y en contrapunto entre sí.

Esta visión más plural del futuro también resalta de trabajos más recientes en antropología que, a raíz de experiencias dramáticas y de los cambios drásticos vividos como resultado ya sea del periodo de violencia en Guatemala, de la rebelión zapatista en Chiapas o de las migraciones recientes y lejanas, permiten atisbar la complejidad de las relaciones entre agentividad, decisión personal y el tiempo histórico tal como lo conciben y lo forjan las sociedades mayas (Metz 2006, Bergeret 2012, por ejemplo). En ámbitos más íntimos, nuevos enfoques de investigación como aquellos sobre la socialización nos incitan por su parte a observar de manera más minuciosa la fábrica de los múltiples intercambios y actitudes que forman el día a día de las diversas esferas de vivencia mayas (de León Pasquel 2005, Gaskins 2000, entre otros).

En las páginas que siguen, nuestra intención es desvelar dicha pluralidad futurista, a partir de un análisis de las formas de proyección en el porvenir

1. Además algunos hechos pueden ser sujetos a interpretaciones opuestas. Así, si el futuro está ubicado detrás, como lo describe Schumann (1981) para el tojolabal, es muy probable que sea como en otras lenguas (por ej. en aymara, Núñez \& Sweetser 2006) según una oposición epistémica visible (delante) / no visible (detrás), lo que plasma el futuro no tanto en el pasado sino en lo desconocido. Considerar que la metáfora del detrás para el futuro corresponde a ubicarlo en el pasado, parece por ende resultar más bien de la proyección de nuestra visión del "pasado hacia atrás" sobre la construcción tojolabal del "futuro hacia atrás", lo que en efecto hace coincidir pasado y futuro en un mismo espacio, pero por un entrecruce de concepciones desligadas y no por razones internas al idioma tojolabal. 
que se encuentran gramaticalizadas en la lengua maaya (maya yucateco) y que los hablantes movilizan en diferentes tipos de interacciones y géneros verbales. Dichas formas lingüísticas no agotan, por supuesto, los ámbitos y modos posibles de proyección prospectiva constituyentes de las experiencias diarias, y menos diarias. Empero, las formas gramaticales expresan modos típicos de posicionarse y proyectarse, fácilmente disponibles, más accesibles lingüística y, a priori, cognitivamente, comúnmente usados, y provenientes de procesos de sedimentación - a veces aún en curso- de modos de vincularse con los acontecimientos y con los demás en el marco de las prácticas discursivas (Hanks 1990; Enfield 2002; Kockelman 2010).

El análisis tiene in fine dos objetivos principales: en primer lugar, la explicitación y la comprensión de esquemas semánticos, pragmáticos y cognitivos implicados por las formas lingüísticas y sus usos; en segundo lugar, el aporte de un nuevo vector de comprensión (los índices lingüísticos) a las temporalidades cotidianas, históricas y rituales. Ambos objetivos integran una perspectiva comparativa, desde el cercano ámbito maya hasta el lejano más allá. Pero lo que más nos interesa mostrar en el marco del presente trabajo, es que la temporalidad debe entenderse, más allá de la localización y la métrica temporales y calendarias, como una textura espesa, una urdimbre donde se entrelazan los hilos del flujo del tiempo con aquellos de las formas de control sobre la acción, de la aprehensión de la causalidad, de los posicionamientos epistémicos, de las relaciones intersubjetivas.

Las formas lingüísticas analizadas en este articulo (prospectivo inminente $m i k\left(a\right.$ 'aj), proyectivo y deóntico yan, desiderativo ta(a)k, asertivo je 'el... $e^{\text {', }}$ proximativo ta'ayt, predictivo bíin) fueron elegidas porque son las más gramaticalizadas y forman paradigma, en posición inicial de verbo. No nos detendremos aquí sobre sus propiedades morfosintácticas y los lazos que entretienen con otros paradigmas, ni tampoco sobre los marcos temporales que algunas comparten con las formas retrospectivas especialmente (véase en particular Bohnemeyer 1998, 2010; Vapnarsky 1999, 2016, y las referencias ahí citadas). Dejamos asimismo de lado la forma prospectiva ken, propia de las construcciones de focalización, que expresa una prospectividad muy neutra puesto que sirve precisamente para enfocar otro constituyente de la frase ${ }^{2}$.

El análisis parte de la observación de prácticas verbales entre los mayas del centro de Quintana Roo. Los ejemplos analizados provienen de decenas de horas de grabaciones y notas de campo en contextos variados de la vida cotidiana y menos cotidiana, que realizamos desde 1994 en pueblos al sur del municipio de Felipe Carrillo Puerto (K'opch'e'en, San Andrés, Noh Kah). Se trata de la región de los denominados cruso'ob o máasewaal, donde los mayas rebeldes de la guerra de

2. Otras formas aspectuales pueden ser usadas para referencia futura en yucateco, como el incompletivo $k$ - o el progresivo táan, pero nos centramos aquí en formas inherentemente prospectivas. 
Castas se instalaron a mediados del siglo XIX y fundaron un territorio autónomo, regimentado por un poder teocrático y legitimado por cultos a oráculos divinos, hablantes, profetizantes (Villa Rojas 1978 [1945]; Dumond 2005; Sullivan 1983). Es probable que las expresiones analizadas muestren ciertas variaciones dialectales a través de la península. Y de hecho, ciertos procesos de gramaticalización y/o resemantización están vinculados al contexto socio-histórico y cultural de la subregión de estudio, como lo veremos más adelante.

En la siguiente sección 2, recordamos que la cuestión de la pluralidad de futuros se ancla a problemáticas teóricas y comparativas más amplias. En la sección 3, iniciaremos nuestro análisis de las formas usadas para expresar eventos y situaciones futuras en maya yucateco con una sinopsis de su conjunto. Luego, los usos y valores de cada forma serán estudiados detalladamente, empezando con aquellas que expresan una relación más directa con las potencialidades de los individuos hablantes y terminando con el predictivo, especializado para el futuro histórico. Veremos en 4 cómo en el género de los discursos sobre el futuro histórico sólo algunas de las formas prospectivas son usadas, y por qué. Por fin, concluiremos en la sección 5, sacando a luz la urdimbre de valores aspecto-temporales, agentivos, epistémicos y aléticos, dialógicos e intersubjetivos, e interaccionales que conforman la referencia al futuro, y lo que caracteriza su expresión en maya yucateco.

\section{Marcos temporales: plurales y compuestos}

La visión de un futuro pasado se distingue de la representación generalmente admitida del futuro como ámbito de lo desconocido, incierto e imprevisible. Dicha representación fundamenta o permea fuertemente los análisis de las concepciones culturales y lingüísticas del tiempo. En antropología, por ejemplo, muchas formas rituales se explican como modos de controlar la recurrencia temporal y realzar o forjar las repeticiones cíclicas en el flujo incierto de los acontecimientos. En lingüística, la indeterminación inmanente del futuro a nivel físico o fenomenológico es comúnmente avanzada para explicar el hecho de que, en las lenguas, el futuro se expresa a menudo por marcas modales más que temporales, como reflejo de la apertura de posibles inherente al porvenir. Empero, dicha explicación sólo puede ser parcial, porque considera abusivamente la estructura lingüística en una relación de correlación directa con las propiedades físicas o fenomenológicas del tiempo, y porque ignora la pluralidad de modos de aprehender el tiempo, que pueden coexistir intracultural y lingüísticamente, en la mente de un mismo ser hablante, además de diferencias entre culturas y entre lenguas (Vapnarsky 2016).

Varios análisis, desde la escuela de Praga hasta autores recientes en el campo de la lingüística cognitiva, han recalcado el hecho de que la gramática de la temporalidad de las lenguas implica la coexistencia de subsistemas paralelos, dependientes de los tipos de procesos y eventos referidos, de los contextos enunciativos y los géneros discursivos implicados. Así, distintos contrastes 
fueron propuestos para identificar la oposición observada en las lenguas entre formas modo-aspecto-temporales que sirven para referir a acciones o eventos que se hallan en una esfera de conexión y control potencial del hablante versus otros en disociación, en particular: referencial actualizado/no actualizado (Desclés and Guentchéva 2011), tiempo del discurso/tiempo de la historia (Benveniste 1966), present relevance/non present relevance (Fleischman 1982), intention-based/prediction-based futures (Dahl 2000), connection/disconnection (Novakova 2001), contemporal/non-contemporal (o cognitively dissociated temporal domain) (Botne and Kershner 2008). En ese marco, el "futuro pasado" maya se podría entender como un futuro desconectado fenomenológicamente de la esfera de capacidad de acción de los hablantes, lo que hemos en cierta medida propuesto en nuestro estudio sobre el futuro predictivo bíin (Vapnarsky 2016). No obstante, para confirmarlo y acceder a una mejor comprensión de otros modos posibles de aprensión del porvenir, cabe analizar el conjunto más amplio de formas prospectivas que existen en yucateco.

Para el análisis, adoptamos el concepto de Desclés y Guentchéva $(2011,2012)$ de referenciales temporales, que corresponden a referenciales propios al discurso y se distinguen de los referenciales externos (físicos, cósmicos...). Dichos referenciales se caracterizan por usos específicos de las expresiones temporales que posee cada lengua. Los autores contrastan dos tipos principales, el referencial enunciativo, que se ancla directamente a la situación de enunciación y al proceso enunciativo, y referenciales no-actualizados, que manifiestan cierta forma de desconexión con dicha situación (referencial mítico, histórico, ficcional, ...). El concepto de referencial temporal permite dar cuenta de, y en cierta medida formalizar, los sistemas temporales coexistentes en las lenguas y su conexión con distintos tipos de prácticas comunicativas y planos de aprehensión de la realidad. Pero la hechura y conformación precisas de los referenciales y la forma específica en qué se distinguen entre sí es propia a cada lengua y tradición verbal.

Análisis recientes en cognición han considerado una noción más restringida, la de marco de referencia temporal (Boroditsky 2000; Bender et al. 2010; Tenbrick 2011; Evans 2013), adaptada generalmente de los trabajos sobre marcos de referencia espaciales (Levinson 2003). Dichos análisis se han centrado más que todo en los modos de localización de los eventos y el uso muy común entre las lenguas de metáforas espaciales para hablar del tiempo. Para las lenguas mayas, Brown (2012) muestra el amplio repertorio de formas disponibles en maya tseltal expresar conceptos temporales y la variedad de marcos de referencia temporal que implican (relativos/deícticos como vector dinámico o secuencia estática, absolutos bajo formas cíclicas o unidireccionales y lineares, orientado verticalmente...). Recalca también la pregnancia del espacio como ámbito fuente de términos y metáforas para hablar del tiempo. Le Guen (2012; 2017, en esta publicación) insiste por su parte en la predominancia en maya yucateco del marco de referencia cíclico, aunque otros tipos de marcos de referencia temporal también coexisten en ese 
idioma. Al partir de modelos heurísticos diseñados para tratar del espacio, muchos de los análisis en este campo, en particular en su vertiente cognitiva experimental, tienden a considerar los eventos o procesos como simples objetos a localizar en un trasfondo: el tiempo; también tienden a dejar a un lado ciertos conjuntos de formas o ámbitos semánticos que los idiomas han desarrollado para expresar perspectivas temporales de manera más híbrida y experiencial. En contraste y complementariedad, y en continuidad con la perspectiva preconizada por Hanks (2005) para el análisis del campo deíctico en yucateco, nuestra investigación parte del principio que en el curso del habla natural, la acción es más que un objeto, y la localización sólo es una faceta de la aprehensión del tiempo. Está íntimamente asociada con, y a veces subordinada a otros parámetros que conforman la percepción, interpretación y expresión de los acontecimientos en su transcurso temporal.

Así, los referenciales que consideramos están vinculados con ámbitos semánticos y pragmáticos más diversos que lo "estrictamente" temporal. En su análisis extenso del maya yucateco, Bohnemeyer (1998, 2002, 2010) describe un sistema lingüístico que no usa expresiones del tipo "antes" y "después" y en el que la morfología verbal básicamente no codifica tiempo deíctico. Explicita cómo la referencia temporal se construye mediante inferencias basadas esencialmente en el rico paradigma de marcadores aspectuales que posee esa lengua. Dado que, en efecto, en los predicados verbales las lenguas mayas privilegian la expresión y gramaticalización de información aspectual - es decir de la configuración interna del proceso- a la ubicación cronológica, observamos detalladamente en nuestro análisis los enfoques procesuales y la frontera espesa -es decir aquí las diversas formas de transición que caracterizan la entrada en un proceso- que puede constituir la proyección de una acción (Desclés 2002; Monod Becquelin 2012). Escrutamos también la posible presencia de una referencia temporal deíctica. Coincidimos en descartarla como principio organizador del sistema morfológico verbal, pero contestamos una visión tenseless absolutista. Más ampliamente, prestamos una atención especial a parámetros cuya codificación ha sido realzada en otros conjuntos de formas deícticas y/o temporales de las lenguas mayas: la oposición entre acceso simétrico/asimétrico al referente y el tipo de marco de participación (Hanks 1990, 2005), el parámetro de intersubjetividad (Bergqvist 2008; 2017, en esta publicación), el control o ausencia de control sobre la acción (Vapnarsky 2013a), el tipo de compromiso y posicionamiento frente a la acción en cuestión (commitment, Kockelman 2004, 2010). Finalmente, como es común entre las formas lingüísticas usadas para la referencia al porvenir, las modalidades epistémicas y deónticas son también de consideración esencial.

\section{Proyectarse en el futuro: los modos del maya yucateco}

La expresión de la temporalidad en maya yucateco se reparte en diversos elementos de la frase, de gramaticalización y grado de obligatoriedad variadas. 
Consideramos aquí expresiones que forman parte del amplio conjuntos de marcadores iniciales tempo-modo-aspectuales del predicado verbal. Estos elementos seleccionan sufijos posverbales que aportan informaciones aspectual y modal más abstractas, asociadas con la de transitividad (Bricker 1981b; Bohnemeyer 1998; Lois y Vapnarsky 2003; Vapnarsky 1999, 2016). Dichos sufijos no serán abordados en este análisis que se enfoca en los valores semánticos y pragmáticos de los marcados iniciales, por corresponder éstos a un nivel del lenguaje que es el resultado más palpable de procesos de sedimentación de posicionamientos interlocutorios repetidos $\mathrm{y}$, a su vez, un nivel más accesible a opciones discursivas para los hablantes.

\begin{tabular}{|c|c|c|c|c|}
\hline \multicolumn{5}{|c|}{ Marcadores TAM especializados para referencia futura en maya yucateco } \\
\hline $\begin{array}{l}\text { marcadores } \\
\text { iniciales }\end{array}$ & valor & ejemplo & traducción & $\begin{array}{l}\text { marcador } \\
\text { de estatus }\end{array}$ \\
\hline ken & $\begin{array}{l}\text { prospectivo } \\
\text { dependiente }\end{array}$ & $\begin{array}{l}\text { leti'kun suut } \\
\text { leti'ken } u-s u t-e j\end{array}$ & $\begin{array}{l}\text { es ella quien volverá } \\
\text { es ella quien lo devolverá }\end{array}$ & intr: ipf \\
\hline $\begin{array}{l}\text { m/nik(a'ah) } \\
\& \text { sbj (tr.) }\end{array}$ & inminente & $\begin{array}{l}\operatorname{mik}\left(\boldsymbol{a}^{\prime} \mathbf{a j}\right) \text { in-suut } \\
\operatorname{mik}\left(a^{\prime}{ }^{\prime}{ }^{\prime}\right) \text { in-sut-ej }\end{array}$ & $\begin{array}{l}\text { voy a volver/ ahora vuelvo } \\
\text { voy a devolverlo }\end{array}$ & tr: sbj \\
\hline y(a)an & $\begin{array}{l}\text { proyectivo- } \\
\text { deontico }\end{array}$ & $\begin{array}{l}\text { yan in-suut } \\
\text { yan in-sut-ik }\end{array}$ & $\begin{array}{l}\text { tengo que/voy a volver } \\
\text { tengo que/ voy a devolverlo }\end{array}$ & \\
\hline $\begin{array}{l}\text { h(e'el)-... } \\
-\mathrm{e}^{\prime}\end{array}$ & asertivo & $\begin{array}{l}\text { je'el in-suut-e' } \\
\text { je'el in-sut-ik-e' }\end{array}$ & $\begin{array}{l}\text { seguro, volveré/voy a volver } \\
\text { seguro, lo devolveré/ lo } \\
\text { voy a devolver }\end{array}$ & \\
\hline tak & desiderativo & $\begin{array}{l}\text { tak in-suut } \\
\text { tak in-sut-ik }\end{array}$ & $\begin{array}{l}\text { quiero volver } \\
\text { quiero devolverlo }\end{array}$ & $\begin{array}{l}\text { intr: ipf } \\
\text { tr: ipf }\end{array}$ \\
\hline $\begin{array}{l}\text { k'abéet/ } \\
\text { k'a'ana'an }\end{array}$ & necesitivo & $\begin{array}{l}\text { k'abéet in-suut } \\
\text { k'abéet in-sut-ik }\end{array}$ & $\begin{array}{l}\text { es necesario que vuelva } \\
\text { es necesario que lo } \\
\text { devuelva }\end{array}$ & \\
\hline ta'ayt & $\begin{array}{l}\text { prospectivo } \\
\text { proximal } \\
\text { (casi) }\end{array}$ & $\begin{array}{l}\text { ta'ayt in-suut } \\
\text { ta'ayt in-sut-ik }\end{array}$ & $\begin{array}{l}\text { estoy casi volviendo } \\
\text { estoy casi devolviéndolo }\end{array}$ & \\
\hline bíin & $\begin{array}{l}\text { futuro } \\
\text { predictivo }\end{array}$ & $\begin{array}{l}\text { biin suu-n-ak-en } \\
\text { biin in-sut-ej }\end{array}$ & $\begin{array}{l}\text { (un día) volveré } \\
\text { (un día) lo devolveré }\end{array}$ & $\begin{array}{l}\text { intr: sbj } \\
\text { tr: sbj }\end{array}$ \\
\hline
\end{tabular}

Cuadro 1 - Formas (T)AM de futuridad en maya yucateco (cada forma se ilustra en intransitivo y transitivo). 


\section{La inminencia o los principios del comienzo: mik(a'aj)}

La forma mik( $\left.a^{\prime} a j\right)$ (y sus diversos alomorfas mencionados más abajo) indica que una acción está "a punto" de realizarse, lo cual conlleva a menudo que la preparación o los preámbulos que conducen a la acción están llegando a su término (las tortillas están listas y se puede instalar uno a la mesa, un hombre ya preparó sus útiles para la caza y está por salir, el agua se calentó y uno va a lavarse, etc.). Mik(a'aj) visualiza la fase justo anterior al inicio de la acción. Por consiguiente, ésta se ve afectada de un cierto espesor temporal, variable según el proceso y el acto de palabra implicado. Pero no existe un hiato entre la actualización del proceso y el punto de referencia adoptado (a diferencia de ta'ayt, véase más abajo). Al contrario, es una relación de adyacencia o contigüidad con el inicio de la acción que se adopta. Inclusive, mik(a 'aj) puede en ciertos casos servir de ingresivo, ya no se refiere al umbral (justo antes de la acción) sino a la propia entrada en la acción.

$\operatorname{Mik}\left(a^{\prime} a j\right)$ está etimológicamente vinculado al verbo $b i n$ «ir » y tiene variantes alomorficas (bin ERG-ka'aj + verbo $\sim n i k a^{\prime} a j$ o $m i k a{ }^{\prime} a j+$ ERG-verbo; $\sim n i k-\mathrm{ABS}$ o mik-ABS + verbo), que demuestran un proceso de gramaticalización aún en curso, además de diferencias dialectales $(n / m)$ (véase Briceño Chel 1997, p. 57-92 y Vapnarsky 1999, p. 110). La forma de origen es una construcción con el verbo bin "ir" en aspecto progresivo A- $k a$ 'aj (para la formación en $k a^{\prime} a j$, ver Smailus 1989, p. 73).

En el referencial enunciativo, $\operatorname{mik}\left(a^{\prime} a j\right)$ se usa mucho con la primera persona para anunciar la acción que uno emprende casi en el momento de enunciarla. Por ejemplo, al agarrar un balde y ya lista para salir, una muchacha se exclama:

\section{(1) Mik-en chup-ja'! IMM-1B llenar-agua "Voy a buscar agua!"}

Durante la fiesta patronal, un hombre llega al maakan, la enramada, donde hombres y mujeres están cocinando. Uno de los presentes pregunta al recién llegado acerca del avance de la preparación de los panes rituales que se confeccionan al mismo tiempo en la iglesia, y él (H2) responde:

(2) H1: sáam a-pat-e'ex?

H.RTR 2A-moldear-2PL

"¿Ya los formaron?

H1: sáam a-pat-e'ex?

H.RTR 2A-moldear-2PL

¿Ya los formaron? 


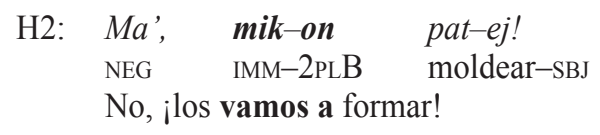

H1: Ko'one'ex pat-waaj! Ko'one'ex yo'os u-séeb-ta! INJ.2PL.INCL formar-tortilla INJ.2PL.INCL FINALIDAD 3A-rápido-INCH ¡Vamos a formar panes! ¡Vamos para que sea rápido!” [makan-2007]

Ese tipo de uso se integra a las prácticas cotidianas donde el anuncio con mik( $\left.a^{\prime} a j\right)$ se ha de concebir como parte integrante de la acción, un enunciado que permite la coordinación entre actividades. Esto se ve confirmado por la combinación frecuente de mik( $\left.a^{\prime} a j\right)$ con compuestos con objeto incorporado (en los ejemplos mencionados chup-ja' 'llenar agua' pat-waaj 'formar panes'), una categoría léxica que refiere principalmente a actividades culturalmente habituales o típicas (Mithun 1984, Lois y Vapnarsky 2003, p. 30).

Puesto que mik( $\left.a^{\prime} a j\right)$ implica una entrada en la acción-que ésta aún esté por ocurrir o ya ocurriendo-, la forma se ve a menudo asociada a una interpretación agentiva, la cual puede corresponder a una toma de decisión y a la inmediatez, sino a la urgencia, de su cumplimiento. Se ilustra con el ejemplo siguiente, en el cual un hombre explica cómo uno se puede hartar de las exigencias del arux, un ídolo vivo, y decidir destruirlo. La intención y decisión se expresa con $m i k\left(a^{\prime} a j\right)$, aquí en una forma intermedia con bink.

(3) Komparasyoone'wáa ts'o 'ok unáaka yóol máak utsente te’ turancho beya'.

"Una comparación, si se cansa uno de alimentarlo en su rancho así

Kawa'ake' "Ts'unáakl inwóol intséentej, wáa múuchukpajl inwóo.

Dices: 'Ya me cansé de alimentarlo, o ya no tengo paciencia para ello.

Bink inw-óop'-jats'-t-ej!”
IMM 1A-quebrar-azotear-TRZER-SBJ
¡Lo voy a quebrar en pedazos!' que dice

No obstante, cabe recalcar que los valores de intencionalidad y control no siempre están presentes y se los ha pues de considerar no tanto como inherentes a la forma, sino como inferidos contextualmente y asociados por tipicidad. Como lo vemos en el ejemplo siguiente, $m i k\left(a^{\prime} a j\right)$ puede ser usado con un proceso claramente pacientivo (la muchacha en nada quería morir): 
(4) Ka'afyak-e' $\quad k i$

Antes.de.ayer $-\mathrm{TD}_{4} \quad \mathrm{CIT}$

"Antes de ayer, dijo,

$\begin{array}{llll}x \text { 'xu'-naj }^{\prime} & \text { le } & \text { nukuch máak-o'ob-o', } & k i \\ \text { silvar-INTR.CP } & \text { DET } & \text { grandes persona-3pl-TD } & \text { CIT } \\ \text { los grandes hombres (espíritus del monte) silbaron, dijo } & \end{array}$

$\begin{array}{lllll}\text { tumen } & \text { bakan } & \text { bin } & \boldsymbol{u} \text {-ka'aj } & \text { kíim-il } \\ \text { CAUSA } & \text { de veras } & \text { IMM } & \text { 3A-IMM } & \text { morir-ICP.INTR }\end{array}$

porque, de veras, estaba por morir

$\begin{array}{lcrl}l e & \text { 'ootsil } & \text { in-'iija-a', } & \text { ki } \\ \text { DET } & \text { pobre } & \text { 1A-hija-TD } & \text { CIT } \\ \text { mi pobre hija, dijo" } & {[\text { Jua-6-1994] }}\end{array}$

En las narraciones, mik( $\left.a^{\prime} a j\right)$ confiere un sentido de rapidez de sucesión. Por lo tanto funciona como uno de los tantos elementos que sostienen la búsqueda de dinamicidad propia al arte narrativo maya. Es notorio señalar, en ese género, la frecuencia de series de acciones enunciadas con el terminativo $t s^{\prime}\left(o^{\prime} o k\right)$ (que, en una suerte de simetría con $m i k\left(a^{\prime} a j\right)$, focaliza el estado resultante, el momento justo después del cumplimiento de la acción), seguido por el prospectivo $m i k\left(a^{\prime} a j\right)$, como si las franjas de la acción cobraran tanta importancia como su "interior" -sino más-, como si los momentos de cambio y sucesión fueran más relevantes que las acciones en sí. Dicho uso se puede observar en el ejemplo siguiente, sacado de la descripción de un ritual de looj kooral.
ts'-u-liisto-tal
ts'óok
tuláaka,
TERM-3A-listo-IPF.INCH
terminar-3B
todo
“ya está alistado, ya todo está terminado

$\begin{array}{llllllll}\text { mikaj } & \text { reesar-e } & k^{\prime} u b-b i & l e & \text { graasya } & \text { yóok' } & e & \text { meesa, } \\ \text { IMM } & \text { rezar- } \mathrm{TD}_{4} & \text { entregar-PART } & \text { DET } & \text { ofrenda } & \text { sobre } & \text { DET } & \text { altar }\end{array}$

ts'-u-jáal-a tuláaka $\quad$ ts'-u-beet $\quad u-x=n a a b a l-i l-o$ ',

TERM-3A-desenterrar-IPF.PAS todo TERM-3A-hacer $3 \mathrm{~A}-\mathrm{FEM}=$ pan.ritual-REL-TD 2 ya los desenterraron (del horno de tierra), todo, ya hicieron sus panes rituales
mukaj bin ch'a-bi
tun le
Jwan T'ul-o',
IMM.3A ir agarrar-PART 2 CONCLUSIVO DET
Juan T'ul- $\mathrm{TD}_{2}$

están por ir a buscarlo pues al Juan T'ul' [Tor-2(083)] 
Otra particularidad, excepcional en el marco de los marcadores de prospectividad en maya yucateco es la incompatibilidad de los predicados introducidos por $m i k\left(a^{\prime} a j\right)$ con modalizaciones por partículas epistémicas o aléticas, relativas a la probabilidad, la certeza o la necesidad, o no, del cumplimiento de la acción anunciada. Nos encontramos con $m i k\left(a^{\prime} a j\right)$ en un punto tal de emergencia de la acción, que la cuestión de la probabilidad o la veracidad ya no se plantea.

En suma, en el referencial enunciativo, las expresiones con $m i k\left(a^{\prime} a_{j}\right)$ pertenecen primeramente al ámbito de la praxis. Se observó en primer lugar, con su valor anunciador, hasta resolutivo, en segundo lugar, en el hecho de que expresan a menudo un dominio del sujeto sobre la acción, aun si mik(a aj) no codifica el control, y por último, en la manera en que se integran a las formas de coordinación de las acciones en curso... De ese modo, mik(a aj) -aunque su significado sea primeramente aspectual- está íntimamente ligado a ámbitos del hacer y tomar conciencia en la subjetividad y corporeidad del enunciador. Señalamos que el prospectivo inminente toma su origen en una construcción con el verbo bin 'ir'. En las lenguas conocidas, los futuros en "ir" tienden a referir a un futuro en conexión fenomenológica directa con el ahora de la situación de enunciación, u otro punto de referencia (véase Vet 1993, Fleischman 1983, por ejemplo). Esta perspectiva es bastante cercana a la de $m i k\left(a^{\prime} a j\right)$, aunque $m i k\left(a^{\prime} a j\right)$ sea de significado más específico en cuanto a inmediatez y adyacencia al proceso. Veremos además que el yucateco ha gramaticalizado otra forma de pensar el futuro a partir del mismo verbo bin “ir", la del predictivo bíin, cuya perspectiva epistémica y praxémica es en muchas medidas opuesta a mika'aj.

\section{La consecuencia, la planificación y la recomendación: yan}

El proyectivo-deóntico yan ( $\sim$ yaan cuando se enfatiza) inscribe los eventos en proyecciones más amplias que $m i k\left(a^{\prime} a j\right)$. Presenta una acción en relación de encadenamiento con otra que la precede, en base a distintos tipos de determinación: relación de causa a efecto, secuencia esperada, indicación y su cumplimiento, recomendaciones y su seguimiento, decisión y su realización... Por esta razón, es la forma privilegiada para expresar relaciones de consecuencia, conocidas, inducidas o supuestas. Se ilustra a continuación con dos ejemplos. En el primero (6), el locutor habla de kumk' $u$, una entidad ubicada en el centro del mar y cuyos movimientos tienen efectos sobre las lluvias. Mediante el uso de yan, el hablante explicita la relación entre el temblor de kumk'u y la llegada de las lluvias:
(6)
Leti'
$k-u-m e e-t-i k$
$u-k^{\prime} a ́ a x-a(l)$
ja' bey-o', "El hace llover así 
Futuros en contrapunto: proyección, predicción y deseo en maya yucateco

$\begin{array}{llll}u \text {-noojoch-il } & \text { le } & \text { yúun-tsil-o' } & \text { bey-o', } \\ \text { 3A-grande-REL } & \text { DET } & \text { dueño-UNPOS- } \mathrm{TD}_{2} & \text { MAN- } \mathrm{TD}_{2} \\ \text { es el jefe de los dueños (de la lluvia), } & \end{array}$

\begin{tabular}{llll}
$\begin{array}{l}\text { deesde } \\
\text { desde }\end{array} \quad$ - $u$-tít & $u-b a j$ & leti', \\
en cuanto se sacude él, & & 3A-REFL & 3 PR \\
\hline
\end{tabular}

$\begin{array}{lll}\text { yaan } & u-k^{\prime} \text { '́ax-a(l) } & j a \\ \text { DEON } & \text { 3A-caer.del.cielo-IPF.INTR } & \text { agua }\end{array}$

va a/tiene que llover,

$\begin{array}{lllll}\text { una.bez } & \text { mun } & \text { tíit-(i)k } & u-b a j-e & \text { leeti', } \\ \text { COND } & \text { NEG.3A } & \text { sacudir-IPF.TR } & 3 \mathrm{~A}-\mathrm{RFL}^{-\mathrm{TD}_{4}} & \text { 3PR }\end{array}$

si no se sacude él,

mun k'áax-a(l) ja', u-k'al-m le ja'-o' bey-o'

NEG.3 caer.del.cielo -IPF.INTR agua $3 \mathrm{~A}$-cerrar-PFT DET agua- $\mathrm{TD}_{2}$ MAN-TD no llueve, bloqueó la lluvia así."

[explicación sobre Kuumk’u, VVA0086-Mak.1-1996]

En el ejemplo (7), una madre explica cómo se debe cuidar el ombligo infectado de un niño recién nacido. Si se quema bien, entonces se cicatrizará y curará. Yan expresa esta relación de consecuencia.

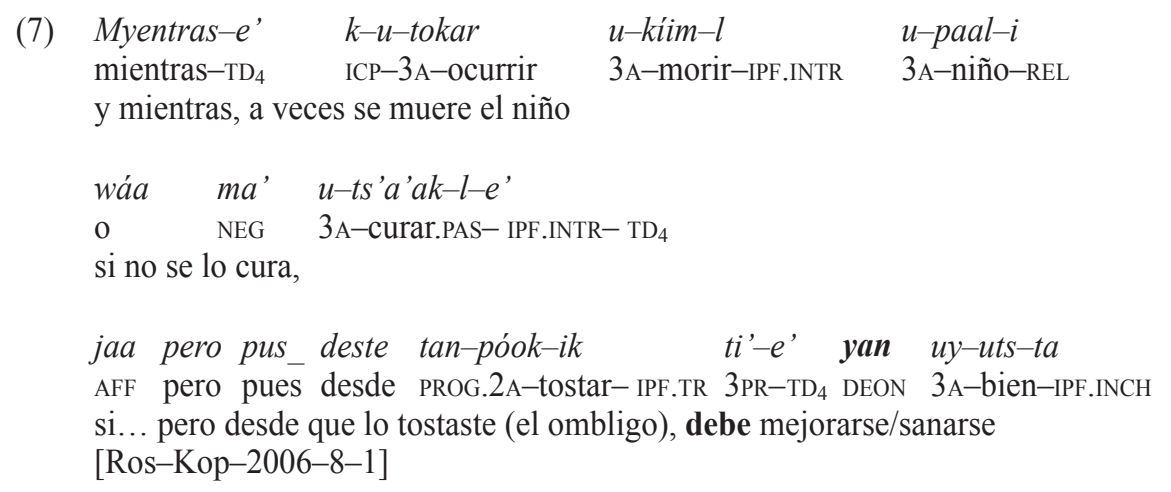

Otro valor de yan se vincula a su uso para expresar guiones típicos de acción o actividades. En este caso, la relación implicada no es tanto de causalidad sino la de secuencias de acciones esperadas. Dichas secuencias pueden corresponder a actividades comunes y un saber compartido, o también a experiencias más individuales, como en el ejemplo (8), a continuación. En este extracto de 
conversación, un hombre cuenta que cada noche un anciano viene a visitarle en sus sueños para anunciarle presagios e indicarle cómo ha de comportarse frente al futuro presagiado:

(8) sino kee le chen chiliken j weene te' nooche béejlaka' "porque cuando me acostaba a dormir de noche como hoy

sino ke teene' yan u-taal jum-p'e nojoch máak u'-aabisaar teen, conj Conj 1PR DEON 3A-venir un-CN gran persona $3 \mathrm{~A}-$ avisar $1 \mathrm{PR}$ porque yo, un anciano tenía que venir a avisarme,

$\begin{array}{lllll}\text { yan } & u \text {-'aabisaar-t-ik } & \text { jum-p'e } & \text { nojoch } & \text { máake' } \\ \text { DEON } & 3 \text { A-avisar-TRZER-IPF.TR } & \text { un-CN } & \text { gran } & \text { persona- } \mathrm{TD}_{4}\end{array}$

tenía que avisar un anciano.

teeche 'iijo bey ken 'úuchu techa' bey ken 'úuchu tech teeche'ma'a biin!

Tú, hijo, así es lo que te va a suceder, así es lo que te va a suceder ¡no vayas!

P'aaten pendyeente ti jump'e nuugar, yaan ba'ax kutaal uk'iin tawóok'ol!

Quédate pendiente en un lugar, ¡hay cosas que se anuncian para ti!

Pos tenée'le ba'a beyóo'jach beyóo', kwaando yan inkoosecháa'e'

Pues yo, eso, de veras era así, cuando tenía mi cosecha

yan in-wayak'-t-ik, yan in-wayak'-t-ik

DEON 1A-Sueño.premonitorio-TRZER-IPF.TR DEON 1A-Sueño.premonitorio-TRZER-IPF.TR

tenía que soñarlo, tenía que soñarlo,

k-uy-a'al-a teen yan u-yaan-tal in-kosecháa,

ICP-3A-decir-IPF.PS 1PR DEON 3A-EXIST-IPF.POSIT 1A-cosecha

me decían que iba a tener mi cosecha,

yan inw-il-ik xan le ba'ax ken yaan-ta ten-e'

DEON 1A-ver-IPF.TR también DET cosa PROS EXIST-IPF.POSIT 1 PR-TD $_{4}$

tenía que ver también lo que tendría,

tulaaka yan in-wayak'-t-ik,

todo DEON 1A-sueño.premonitorio-TRZER-IPF.TR

todo, tenía que soñarlo,

'aantes $\quad u-s i$ ' $i-b i \quad$ teen-e'

antes de que me la regalaran (la cosecha),

yan in-wayak'-t-ik táan-il

DEON 1A-sueño.premonitorio-TRZER-IPF.TR frente-REL

tenía que soñarla también.” [VVA0091-Mak.14-1996] 
Los usos de tipo "guion típico de acción" se revelan también en las indicaciones técnicas que nutren los intercambios verbales en situaciones de realizaciones prácticas, materiales, o instrumentales. Observamos en (9) el extracto muy breve de una conversación entre dos mujeres que están preparando tamales en la cocina de M1; M1 usa yan para confirmar o recordar acciones que se han de realizar en una secuencia de acción ya predefinida:

(9) M2: séeb kuntaja

"Va a cocerse rápido

M1: séeba'an!

$\mathrm{Si}$

¡rápido!

M4: $a a$

masáa?

Jaa, ¿no

cierto?

M1: munsáanta ts'oka'an bey ma'ya'ab

En poco tiempo estará terminado, como no es mucho...

M2: $\quad \mathrm{mmm}$

$\mathrm{Mmm}$

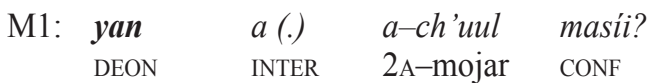

¿Tienes que mojar, no cierto?

M4: jaaa

Sí

(...)

M1: máa' si yan in-ts'ak-o'on je'

NEG ENF DEON 1A-poner-1PL huevo

¡Pero si tenemos que ponerle huevo!” [D3-G5-2006]

La segunda función principal de yan, relacionada a la de proyectivo, es la de deóntico. Yan sirve para formar directivos, pero tiene entonces un valor más de recomendación que de orden (para dar ordenes, se tiende más bien al empleo del imperativo, Vapnarsky 2013b). Así, en (10), una madre indica a su hijo que tiene que ir a llevar una llave (en un intercambio anterior, el niño le contó que la maestra se lo había pedido):

(10) Wa bey-O' chiko! Yan a-bin bi-S-aj-yaabe
HYP como-TD PN $\mathrm{TD}_{2}$ DEON 2A-ir ir-CAUS-AP-llave
"Si así es ¡Chico! Tienes que ir a llevar la llave." [D3-G2-2006] 
En una conversación mucho menos trivial, un hombre cuenta cómo al morirse, su padre, un jmeen, especialista ritual, le anunció que tendría ahora que seguir él su trabajo de jmeen.

pwes ka 'ili' túu náats'l uyoorail ukíimlo' táan ya 'ake'
y cuando vio que estaba acercándose la hora de su muerte, decía:

teech kan-p'áata iijo yan a-séeguer-t-k u-jo'ol in-meyaj-a'. 2PR PROS.2A-quedar hijo DEON 2A-seguir-TRZER-IPF.TR 3A-cabeza 1A-trabajo-TD "Tú vas a quedarte, hijo, debes seguir a la cabeza de mi trabajo.

Tumeen inmeyaj inchúunsma' pus yan a seguertik.

Porque este mi trabajo que empecé, pues tienes que seguirlo.” [Tor-Kop-2006-10]

En una franja donde los valores deóntico y epistémico se superponen, yan se usa para el futuro de los proyectos individuales, para expresar intenciones y decisiones personales, a menudo meditadas o razonadas, y regidas por ciertas normas. En el caso de yan, dichas decisiones son relativas a proyectos previstos con un cierto margen de anticipación, a diferencia de mik(a'aj) que lleva de inmediato a la acción. En ciertos casos, una expresión con yan posee un valor performativo fuerte de compromiso para sí mismo, y frente a los demás. Es más, a veces es un requisito para dicho compromiso. Un ejemplo paradigmático se observa cuando una persona se compromete a asumir un cargo ritual, en particular durante las fiestas patronales. Estas incluyen una ceremonia en la cual los participantes aceptan tomar cargos para la fiesta del año entrante. Deben hacerlo con yan en uso de predicado independiente: "Yaan!". Más sencillamente, quien enuncia con yan que irá a encender una vela en honor de algún santo, debe cumplir, y de no hacerlo, incurriría un castigo del santo. En estos contextos, una expresión con yan corresponde a una verdadera promesa, en el sentido religioso. Por esta razón, y para evitar comprometerse frente a dios o a un santo cuando subsiste la menor incertidumbre, se recurre a menudo a elementos que modalizan y atenúan la fuerza ilocutoria de yan, o más comúnmente aun, a expresiones alternativas, como ma' xan ka xi'iken "no es imposible que vaya", típicamente usada en contexto religioso para evitar el compromiso.

Similarmente a mik( $a^{\prime}$ aj), yan no codifica la intención. En el caso de yan, es la proyección de una acción hacia sí mismo en el marco de una determinación o causalidad definidas que tiene como efecto expresar la intencionalidad. A diferencia de mik(a'aj), los predicados con yan pueden ser mitigados de diferentes maneras. El evento introducido por yan está esperado, aconsejado, planificado, pero el locutor puede relativizar la probabilidad o certeza de su realización. Y al fin y al cabo, el evento puede no cumplirse. Un enunciado con yan invoca un curso de acontecimientos previstos; en el caso del compromiso personal, representa un 
primer paso en la acción; y en todos los casos, implica un estado preliminar a la acción, que constituye ya sea su causa ya sea una etapa concatenada en una serie determinada. Pero yan no refiere a la entrada misma en la acción, tal como lo hace $m i k\left(a^{\prime} a j\right)$. Yan se asemeja a $m i k\left(a^{\prime} a j\right)$ por poder ser usado para una decisión personal de cumplimiento de la acción, pero difiere de éste por implicar siempre un desfase en el tiempo entre la decisión y el inicio de la acción. Yan corresponde a una toma de decisión (por lo común, meditada) mientras que mik (a aj) corresponde a la decisión que conlleva a la acción, in situ, en la inmediatez de la enunciación.

En términos diacrónicos, el lazo entre el valor deóntico y los valores epistémicos de yan queda un tanto incierto. Si tomamos en cuenta los procesos de gramaticalización más comúnmente hallados en las lenguas, sería de esperar que el valor deóntico fuera el de origen y que se hubiera luego extendido a relaciones de necesidad de realización más amplias (consecuencia, guion, planificación...). Pero los datos etimológicos no corroboran de manera clara dicha hipótesis. A la inversa, la muy probable relación etimológica entre el existencial yaan y el proyectivo-deóntico yan, y el tipo de usos reportados en los diccionarios coloniales, inducen a pensar que el camino de extensión semántica pudo más bien haber sido el siguiente: existencia $=>$ necesidad de existencia $=>$ necesidad de hacer. Partículas existenciales constituyen de hecho otra fuente para la formación de futuros o prospectivos reportada en diversas lenguas (Heine y Kuteva 2002). Se requiere análisis diacrónico más detallado para poder entender la evolución semántica y pragmática precisa de este morfema.

Las ganas y el deseo: ta(a)k

Otro modo de proyección hacia el futuro, mucho más experiencial, subjetivo y personal es el de las ganas y el deseo, expresado por ta(a)k. Tak (probablemente relacionado etimológicamente con la conjunción tak "hacia") implica, de hecho, una identidad referencial entre el sujeto del deseo y el sujeto de la acción deseada.

En sus usos más comunes, tak se emplea para sensaciones fisiológicas e internas: tener ganas de comer, dormir, orinar, vomitar... (Smailus 1989; Bohnemeyer 1998). No se trata de un querer agentivo sino de unas ganas que nacen y se desarrollan de manera no o poco controlable.

\section{(12) tak injanal "tengo ganas de comer" \\ tak inwenel "tengo ganas de dormir" \\ tak inwiix "tengo ganas de orinar"}

Tak también puede aplicarse a deseos de semblanza más intencional. Se ve en el ejemplo siguiente, que cuenta con dos ocurrencias de tak. Una madre (M) le explica a otra mujer (R) por qué no se encuentra en casa su hijo mayor, 
el taxista del pueblo (los nombres han sido cambiados). El motivo la lleva a expresar con tak tanto su propio deseo de que su hijo no se vaya de viaje, como el deseo de su hijo de juntar el dinero necesario para la construcción de su casa.

$$
\text { R: ... (à M): Ba'ax ka'ach ubil tech? }
$$
¿Para qué lo querías?

M: Yos inwayik ti'k ujanbisen San Andres Para decirle que me lleve rápido a San Andrés

R: aaj, Poolej, bey inwóojel meeta 'ab fleete ti', sáami', súunajij, Aa, Pool, creo que le pidieron flete, ya hace un rato, volvió,

inwa'ake meeta'ab fleete ti'ka'aten, $\mathrm{y}$ creo que le pidieron otro flete,

chan kooche bisa'ab ast ulaak'semaana.

el cochecito, se lo llevaron hasta la semana próxima.

Tinw-ay-ik ti' ma' tak inw-il-ik u-bin ka'achij, pero... PROG.1A-decir-IPF.TR 3PR NEG DES 1A-ver-IPF.TR 3A-ir CNTRFACT pero Le dije (al hijo que se fue) que no hubiese querido que se fuera, pero...

$$
\begin{array}{lllll}
\text { men } & \boldsymbol{t a k} & u \text {-chuk-bes-ik} & u \text {-toojol } & u-n a(j)-i l . \\
\text { CAUSE } & \text { DES } & \text { 3A-agarrar-CAUS-IPF.TR } & \text { 3A-precio } & \text { 3A-casa-REL } \\
\text { es porque quiere completar el costo de su casa.” [AccessR-03-2008] }
\end{array}
$$

Cabe notar que la madre usa tak y no yan para expresar el deseo de su hijo de reunir el dinero para construir su casa, aun si se trata de planificación. Dicho modo de expresión se inscribe sin dudas en la estrategia general entre los mayas de no expresar de forma asertiva la realización de un objetivo si no se tiene la seguridad de conseguirlo. La proposición es del orden de la intención, en el sentido de una fuerza que anima el hijo a actuar como lo hace (tak)-comparable a la fuerza que impulsa las necesidades fisiológicas-, y no del plan (yan); se expresa en el modo de las ganas-deseos, y no de la voluntad afirmada.

El uso de tak en estos casos indica pues la posible inaccesibilidad de lo deseado, precisamente porque se trata de una forma que expresa un control muy débil de la acción. En los ejemplos más intencionales, el valor de ausencia de control induce la inferencia de que el objeto deseado pueda quedar fuera de alcance, mientras que en el caso de los procesos fisiológicos, la ausencia de control se vincula a la imposibilidad de resistencia frente a la emergencia y el desarrollo de la gana, al carácter irreprensible de dicha sensación.

Un último empleo interesante de tak concierne procesos no humanos. En los contextos siguientes, se vincula a una fuerza interna de transformación télica, 
que como en los casos fisiológicos, se desenvuelve de forma no intencional ni controlable. Puede aplicarse a vegetales $(a, b)$, fenómenos meteorológicos $(c)$ pero también, aunque con menos frecuencia, a artefactos (d, e). En este último caso, el uso de tak refiere a una dinámica de transformación del objeto, a menudo de descomposición, en reacción a fuerzas externas pero no (directamente) agentivas (de un modo similar a lo que expresan las formas medio-pasivas, de las cuales las lenguas mayas poseen ricos paradigmas).

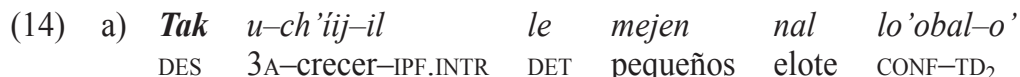
"Quieren crecer-IF.INTR DET pequeños elote CONF- $\mathrm{TD}_{2}$ "Quieren crecer los elotitos, ¡de veras!"

b) Kex tak u-k'an-ta le o'o'tsil chiina, mun-k'an-ta aún DES 3A-maduro-IPF.INCH DET pobre naranja NEG.PROG.3A-maduro-IPF.INCH "Quieren madurar estas pobres naranjas, pero no maduran..."

c) Tak u-k'áax(-al) ja' DES 3A-caer.del.cielo-IPF.POSIT agua "Quiere llover."

d) Tak u-laj-tsi'ik-la'aj in-nok' DES 3A-todo-deshebrar-IPF.REIT 1A-ropa "Mi ropa quiere/está por deshebrarse toda."

e) Tak u-la'ab-l le k'anche'-a', DES 3A-arruinar-IPF.INTR DET asiento-TD "El asiento quiere arruinarse,

$$
\begin{aligned}
& \text { yaan } \quad u-s i i b-i, \quad k-u-c h^{\prime} u \dot{u}-u \\
& \text { EXIST 3A-carcoma-REL ICP-3A-mojar-IPF.INTR }
\end{aligned}
$$

El español posee expresiones con "querer" que parecen equivalentes, sin embargo no es evidente que el uso maya corresponda a un calco del español. Si lo fuera, se esperaría más el uso de la raíz léxica $k$ 'áat, generalmente empleada para traducir querer. El uso de tak en los ejemplos (14) parece más bien responder a configuraciones semánticas convergentes, que se hallan en otras lenguas donde se observa la extensión de formas relativas a sensaciones humanas hacia objetos no humanos (Heine et al. 1991, p. 171). A diferencia de querer, tak señala meramente una ausencia de control, ya sea en la emergencia del deseo, ya sea en su cumplimiento. A diferencia de lo que resalta de los casos estudiados en los trabajos sobre gramaticalización, no se trata de la extensión de usos de una forma volitiva humana a los no humanos con pérdida del valor volitivo o intencional, puesto que, según nuestra hipótesis este valor no existe al inicio. Quizás dicho valor se implante a fuerza de 
usos como los del ejemplo (13), pero queda secundario y depende más que todo de procesos de inferencia. Tak se distingue pues de la volición, y del deseo objetivado y focalizado en un objeto externo, lo que se expresa en yucateco con formas menos gramaticalizadas como $k$ 'áat "querer, pedir, preguntar", $t$ s 'ibóolt "desear, anhelar" o "oot "desear" (> óol "ánimo" + transitivizador).

\section{La aserción, la certidumbre y la proyección dialógica: j(e’el)- ...-e’}

En complemento de expresiones que señalan la proyección y la decisión, se debe considerar el asertivo je 'el-...-e'. Este tiene la característica de construirse como un morfema discontinuo con el clítico terminal $e^{3}$, entrando así en relación con el paradigma de las partículas deícticas, a diferencia de los otros marcadores (T)AM. Según Hanks (1990, p. 264, 286-292), je'el-e' expresa, en sus usos canónicos una certidumbre sin indicios o evidencias perceptuales, se caracteriza por una orientación prospectiva inherente-sin conllevar más precisión temporal-, y se usa también para hechos de validez genérica o verdades generales.

Añadimos que je'el...-e' se emplea en contextos donde el futuro se presenta inicialmente bajo una forma ramificada, una apertura de posibles. En ésta, je'el-

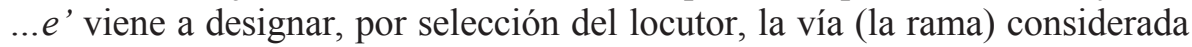
como aquella que sigue el trascurso habitual de las cosas (uso de je'el...-e' para verdades generales) o que seguirá el desarrollo del presente (uso prospectivo de je'el...-e'), y apartando las otras, que aún pertenecían al mundo de los posibles antes del enunciado con je 'el ...e'. El asertivo je 'el-...e ' contrasta así con wal...e', un "quizás" muy polimorfo del maya (Vapnarsky 2012, 2013b). Mientras wal...e” abre posibles, je' $e l . . . e$ ' parte de un horizonte de posibles, y los cierra, señalando un camino único entre las múltiples vías del futuro que potencia el presente.

Tal caracterización permite entender porque je ' $\mathrm{el}-\ldots-\mathrm{e}$ ' aparece en contextos polémicos, que implican una confrontación de puntos de vista, o en afirmaciones contundentes, que se integran a interacciones dialógicas en las cuales el interlocutor acaba de emitir una hipótesis inversa, preguntar y así abrir alternativas, o simplemente dejar lugar a duda. Observamos dicho tipo de aserción en (15), extracto de una conversación sobre las cualidades del sip', dueño de los venados:

(15) Top'-okbal u-baak pero mientras-e' chichan, lel-o' yaan a y-iik'bin. brotar-PART 4 3A-hueso pero mientras-TD ${ }_{4}$ pequeño DET-TD $\quad$ EXIST REL $3 \mathrm{~A}$-aire EV "Sus ramos tienen ramificaciones pero, a pesar de eso, es pequeño, ese tiene su aire dicen

$$
\begin{array}{lll}
\text { Lel-o' } & k-u(.)-\text { pregar-t-ik } & \text { máak. } \\
\text { DET-TD } & \text { ICP-3A-perjudicar-TZER-IPF.TR } & \text { persona }
\end{array}
$$

Ese le perjudica a uno.

3. Segun Hanks (1990, p. 22), e' puede ser definido como un "semantically empty placeholder that contributes nothing to the identification of the referent". 
Futuros en contrapunto: proyección, predicción y deseo en maya yucateco

$$
\begin{array}{llll}
\text { Je' } & u-t o p-k & \text { máak } & \text { k'oja'anil-e } \\
\text { ASS } & \text { 3A-dañar-IPF.TR } & \text { persona } & \text { enfermedad-TD }
\end{array}
$$

Seguro que la enfermedad te daña." [Tor-2006]

La caracterización que proponemos también explica que je'el... e' se use para la expresión de una invitación - la cual permite crear la imagen positiva de una situación donde ya está incluida la participación del interlocutor a la acción-y para la expresión del acuerdo -opuesto por naturaleza a otra vía, la del desacuerdo o del rechazo:

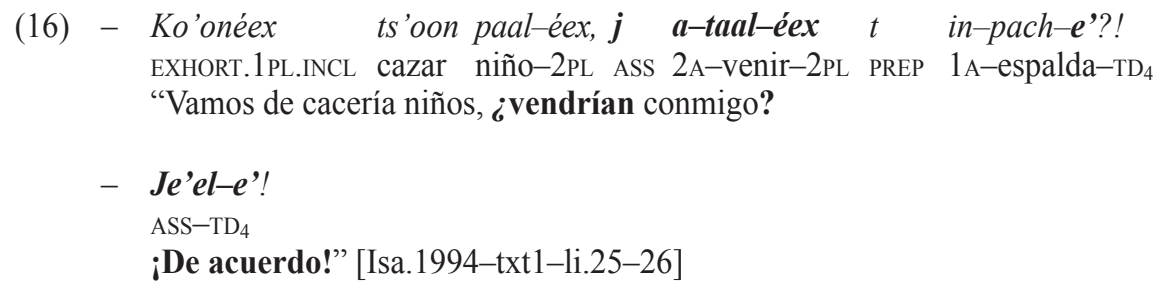

Con valores similares, fórmulas con je 'el ... e'se pueden usar en diálogos rituales, por ejemplo en (17), en un extracto de la aceptación de los músicos de la fiesta patronal a la invitación de ir a tocar para el santo bajo el maakan, la enramada.

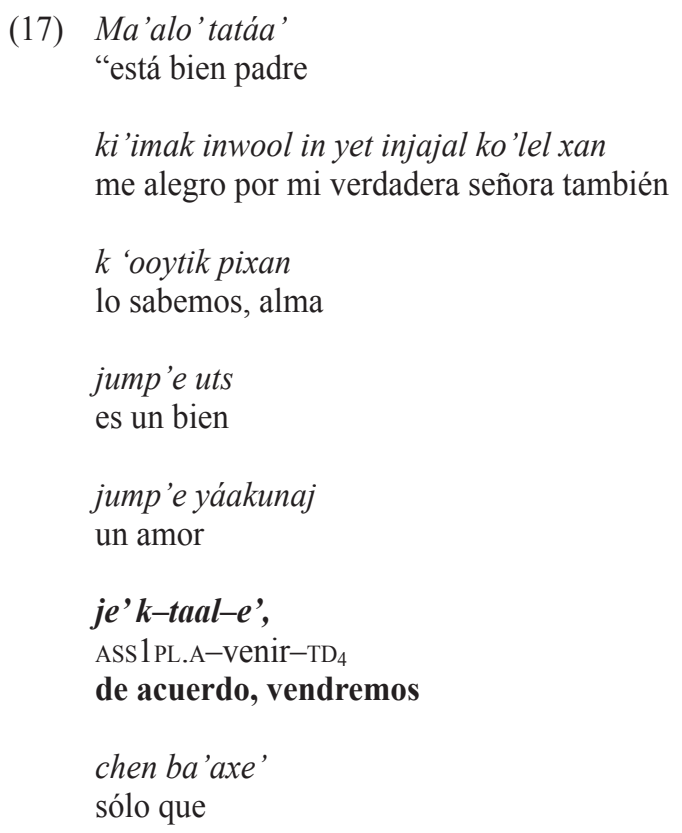


yan atuu'chik'tkóon 'aabiso kwaando liistoéex.

tendrán que mandarnos un aviso cuando estén listos.” [VVA0068-1996-Yan-51]

El esquema de futuro ramificado con selección de una vía subyacente a je'el ...e e' permite entender un último tipo de uso, aparentemente alejado. Se trata del uso común de je'el ...e' en las amonestaciones. Éstas sirven precisamente para cambiar la acción del otro y así la vía que está tomando el futuro. Hallamos ejemplos típicos de ello en los regaños de los padres hacia los niños, dentro del género del k'eeyaj, ilustrado en (18). Los hermanos mayores son generalmente quienes están más directamente a cargo de los menores, pero cuando ellos no les obedecen, lo reportan a sus padres quienes regañan más vehementemente a los pequeños.

(18) Hermana de Nico a su madre:

Maami, le Niiko tunch 'ink e chan paalo'

"Mami, Nico está tirándole piedras al bebé

Madre a su hijo Nico:

Niko, u'uy t'aan!

¡Nico, oye lo que te dicen!

Ba'ax e Niko, Niko $\boldsymbol{j}$ in-top-k-ech t-u-jaaj-il-e'!

que DET NP NP ASS 1A-dañar-IPF.TR-2B CP.TR-3A-verdad-REL-TD 4 Qué pasa Nico, Nico, ¡te la voy a dar de veras!” [D3-G5-2006]

(19) Padre a su hijo:

$$
\begin{aligned}
& \text { ¡Je' in-top-k-ech wal-e'! \& T-aw-uy-aj?! U'uy t'aan! } \\
& \text { ASS 1A-dañar-IPF.TR-2B quizás-TD } 4 \text { CP.TR-2A-oir-PF.TR oír.IMP palabra }
\end{aligned}
$$

“¡Te la voy a dar será! ¿¡oíste?!” ¡Oye lo que te dicen! [D3-G5-2006]

En todos los casos contemplados, ya sea la aserción de verdades generales o la afirmación de una opinión, ya sea la expresión de una invitación o la del acuerdo, y aun la amonestación, el uso de je'el...e', por el modelo de posibles y las confrontaciones de puntos de vista que implica, se presenta como de naturaleza intrínsecamente dialógica. Asegurar, es posicionarse frente a una posición inversa o diferente; invitar es incluir al otro; emitir un acuerdo, es aceptar la realidad y la iniciativa del otro; prometer, es comprometerse frente al otro; amonestar, es tratar de cambiar la acción del otro... En ese sentido, je 'el ... $-e$ ' integra de manera fundamental un componente intersubjetivo, pero también interaccional, si consideramos los actos de palabras que permite efectuar y que implican, mucho más que para yan, el establecimiento de relaciones entre los participantes a la interlocución, relaciones que pueden ser del orden de la negociación de saberes o de la concertación -más o menos dirigida- para 
acciones y actividades comunes. La inclusión morfológica de je'el ...-e’ en el paradigma de los deícticos no es ajena al fuerte anclaje situacional de esta forma.

La proximidad temporal: ta'ayt(ak)

Ta'ayt(ak) (ta'aytak en su forma adverbial larga, ta 'ayt en su forma reducida de marcador preverbal) indica que el proceso contemplado está por realizarse. A diferencia del inminente mik( $\left.a^{\prime} a j\right)$ que expresa una adyacencia con el inicio de la acción, o el momento mismo de su inicio, ta'ayt implica un lapso de tiempo, aunque sea muy mínimo, entre el momento de referencia y el proceso contemplado. Forma un par con su simétrico taantik...e' que se aplica al pasado, y ambas formas presentan, en el conjunto de la veintena de marcadores TAM del maya yucateco, lo que podría corresponder de manera más clara y unívoca a expresiones de métrica temporal. En (20), una madre le pregunta a su hijo acerca de los huevos que su gallina está incubando, ta'ayt focaliza el corto tiempo que falta y no el proceso mismo, como lo hacía tak. En (21), la proximidad está proyectada sobre un referencial narrativo, en base a un ahora equivalente al momento del día del $\mathrm{T}_{0}$ de la enunciación chen ale' walkila' "a estas horas (del día)"; (22) también proviene de una narración, pero esta vez se trata de un dialogo en discurso directo donde el narrador pronuncia como un actor las palabras del protagonista, con una transposición del punto de origen de ta'ayt a la temporalidad de la escena del cuento.

(20) - Jay-p'ée túun u-je' yiij? QUANT-NC CONCL 3A-huevo maduro “¿Cuántos huevos están a punto? (ya para reventar)

- jun... p'ée... 'u-maas-il-o' jach... ta'ayt u-je'e-taj! uno NC 3A-más-REL-3PL muy PROX 3A-huevo-IPF.INCH uno... ja los demás les falta muy poco para reventar!" [Del-access5-je'-27-03-2008]

(21) chen ale' walkil-a', CONJ CONJ ahora.CICL-TD "A estas horas,

ta'aytak u-ka'-bin-o' ich kool tuka'aten, sáan-samal bey, sáan-samal bey ... PROX 3A-REP-ir-3PL en milpa de.nuevo RED-mañana así, RED-mañana así estaban por volver a irse a la milpa de nuevo, cada día era así, cada día era así...” [Ila-1994.1]

$k-y-a{ }^{\prime}-i k \quad b i n-e^{\prime}$ pus máa ts'ok in-ts'ik ja' ti e polk-o' ICP-3A-decir-IPF.TR EV-TD 4 pues NEG TERM 1A-DAR agua PREP DET gordo-TD "Dice que dicen, pues no que acabo de darle agua al [caballo] gordo 


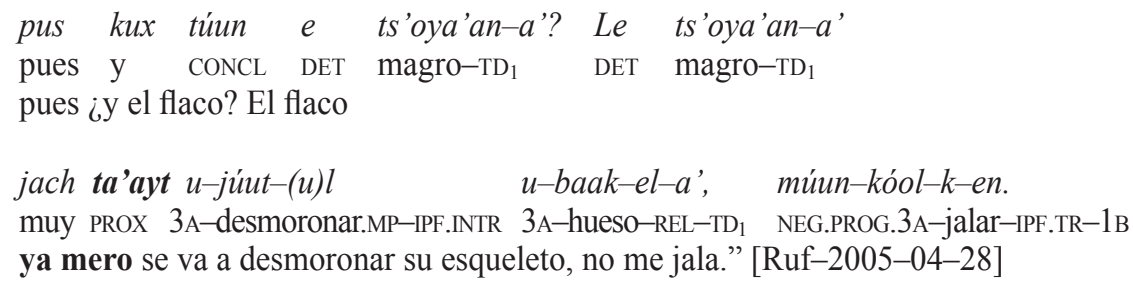

\section{La prediccion y el futuro histórico}

Los modos de referencia al futuro previamente analizados se inscriben más que todo en formas experienciales y dialógicas de aprensión del devenir. El maya yucateco contrasta nítidamente este ámbito del de la predicción fuerte, relativa a acciones predeterminadas y fuera de control humano.

\section{La predicción: bíin}

Dentro de las formas que posee el maaya para presentar una acción o situación por venir, bíin es a la vez la menos usada y en cierto sentido la más fascinante, sobre todo para quien se interesa en los regímenes de historicidad.

El marcador temporal bíin se usa para acontecimientos que conciernen un futuro predeterminado, o más exactamente determinado por un control independiente de la intención y voluntad humanas (Vapnarsky 1996). Sus contextos de empleo son muy específicos: el más común es la citación o evocación de profecías, a menudo formuladas en un modo casi proverbial, del cual biin es un rasgo característico (23), (24). Bíin también puede emplearse para acontecimientos del orden del destino personal, como en (25), enunciado por un joven poco antes de que lo encontraran muerto, como lo reportó su madre. Por último, biin sirve para la expresión de ciertos tipos de promesas, como se observa en (26) enunciado durante un funeral, por un familiar a su primo, al pedirle prestado dinero para la ceremonia.

(23) bíin taal-ak FUT venir-SBJ.INTR(3B) uno-NC huracán “[Un día] vendrá un huracán con trueno, con relámpago.” [Jua12':80]
biin k'uuch-k
u-diya'-il u-síin-il
syeete sa-sak-beej,
FUT 1legar-SBJ.INTR(3B) 3A-dia-REL 3A-estirar-REL siete RED.-blanco-camino
"Llegará el día en que siete rutas (caminos blancos) atravesarán

$\begin{array}{lllll}\text { syeete } & s a-s a k-b e e j & \text { bíin } & \text { síin-ik way táanchuumuk in-kaaj-al-a' } \\ \text { siete } & \text { RED-blanco-camino FUT } & \text { estirar-SBJ.INTR(3в) LOC medio } & 1 \mathrm{~A}-\text { pueblo-NOM-TD }\end{array}$ siete rutas atravesarán aquí por el medio de mi pueblo.” 
Futuros en contrapunto: proyección, predicción y deseo en maya yucateco

$\begin{array}{lllllll}\text { Adyoos bíin } & \boldsymbol{a} \boldsymbol{w}-\boldsymbol{u} \text { 'uy } & \text { uy-a'al-a('al) } & \text { tu'ux } & \text { ken } & \text { in-kím-i } \\ \text { Adios FUT } & \text { 2A-Oir } & \text { 3A-decir-PAS.IPF } & \text { donde } & \text { PROS } & 1 \mathrm{~A}-\text {-morir-IPF.INTR }\end{array}$ “Adiós, [un día] oirás el anuncio de mi muerte." [x-cris.1]

(26) bïin in-bo'-t-ech

FUT 1A-pagar-TRZER-2B

"[Un día] te pagaré."

Bíin no expresa la distancia temporal (en el sentido métrico) sino una referencia temporal vaga (dos mil i piko "el año 2000 y pico") o indeterminada "un día..." Tampoco posee en sí un valor de ciclicidad. Más notorio, en el contexto de las lenguas mayas donde el aspecto predomina, bín está intrínsecamente atado a una referencia calculada a partir del $\mathrm{T}_{0}$ de la enunciación, ya sea el de los locutores presentes, ya sea el de un discurso citado siempre en estilo directo, donde las profecías son enunciadas por divinidades o semidivinidades. En ese sentido analizamos bíin como una forma de tiempo futuro, y no sólo como un prospectivo aspectual (Vapnarsky 2016).

Si bien está atado al tiempo de la enunciación, bíin implica una ruptura de la situación de enunciación en términos de control y agentividad. Bíin refiere a un futuro que no está alejado en términos temporales sino disociado de la esfera de acción de los locutores y participantes. Esto no significa que los acontecimientos referidos no tengan incidencia sobre el presente, ni que los hablantes no actúen en relación a ellos, sino que son presentados como acontecimientos ante los cuales los humanos no pueden concebirse como agentes intencionales y sobre los cuales no pueden tener control directo, a lo sumo una incidencia mediata.

En consecuencia, bíin implica un modelo temporal donde el futuro no es el ámbito de las potencialidades -a diferencia de las formas anteriores-, sino un futuro factual (que presenta el evento como un hecho). Aunque comparte este rasgo con formas de futuro en otras lenguas, el valor de bíin es mucho más específico puesto que está dedicado a un futuro estrictamente predeterminado. Nuestra hipótesis, desarrollada en otros trabajos (Vapnarsky 2009), es que dicho valor resulta de una resemantización de biin íntimamente vinculada a la importancia aguda que tomó el discurso profético a nivel político y religioso entre los mayas cruso'ob de la región.

Por último, cabe subrayar que los empleos proféticos de bíin, que son los más comunes, implican juegos de polifonía a dos niveles. En primer lugar, la polifonía se da en relación con palabras o escritos anteriores a los cuales se vinculan las profecías, con autores o portavoces de los enunciados proféticos. En segundo lugar, la polifonía se fundamenta en relación con un saber colectivo ampliamente compartido y transmitido entre los mayas de edad adulta en esa región. En ese sentido, es también notable que bíin pueda ser matizado por 
formas verbales de incertidumbre, pero una incertidumbre siempre intersubjetiva, y no subjetiva (Vapnarsky en prensa).

Los elementos anteriores nos conducen a definir bín como un futuro que remite a un referencial de acontecimientos disociado de la subjetividad inherente a la situación de enunciación, un plano que transciende al locutor, y que se inscribe ya sea en el tiempo histórico, colectivo, ya sea en el tiempo largo y cíclico del individuo (su vida), un tiempo dependiente de agentes y fuerzas divinos o semidivinos, y no humanos.

\section{Vuelta al futuro... histórico}

Terminamos nuestro recorrido futurístico destacando el vínculo del futuro bíin con un referencial desconectado del control directo y la agentividad humana, vinculado al destino individual y más que todo a la historia colectiva, con sus aspectos predecibles y cíclicos. En contraste, las expresiones de referencia al porvenir analizadas previamente, mucho más comunes en el habla cotidiana, realzaron formas vinculadas a posicionamientos más cotidianos, internos, individuales, práxicos. Mientras que la singularidad de bíin dentro del sistema temporal yucateco (y más generalmente de las lenguas mayas; e incluso mucho más allá, puesto que futuros gramaticales estrictamente especializados para profecías o predicciones de índole similar son muy raros) recae en no poder ser usado para referenciales en conexión directa e inmediata con el enunciador, queda abierta la pregunta inversa, es decir si las otras formas pueden ser usadas para futuros proféticos e históricos. La respuesta es positiva para ciertas formas, en particular el inminente mik( $\left.a^{\prime} a j\right)$ y el deóntico yan, pero con restricciones y efectos semántico-pragmáticos que confirman y completan los valores delineados en las secciones anteriores. El uso de dichas formas revela también cómo se declinan los posicionamientos frente al porvenir en el ámbito de los discursos mayas sobre su historia futura.

El tipo de empleo de $m i k\left(a^{\prime} a_{j}\right)$ con profecías y el contraste entre mik(a'aj) y biin se pueden observar claramente en el ejemplo siguiente que combina el uso de los dos marcadores. Se trata de un extracto de palabras atribuidas a Juan de la Cruz - una figura crística, mesiánica y profética de los tiempos de la guerra de Castas, a menudo asimilada a Ki'ichkelem Yuum, figura maya de Jesucristo-, palabras que suelen recordar los ancianos a pesar de que varias generaciones hayan pasado desde la época supuesta de su enunciación (Vapnarsky 1999, 2009). Se comenta que las palabras fueron pronunciadas cuando Juan de la Cruz, desanimado al ver cómo las fuerzas mayas y mexicanas combatían y se masacraban sin clara victoria, consideró que había llegado el momento de parar las hostilidades, y anunció un periodo de paz durante el cual los mayas podrían gozar de libertad, probar los productos de la gente rica, pero tendrían en contraparte que adoptar ciertas costumbres de sus enemigos. Este periodo se concibe 
como una tregua de duración indeterminada, cuyo término será acompañado por un posible cambio - un retorno al reino de los mayas-, esgrimido en tanto como fuente de esperanza pero también de temor, puesto que aquel término dependerá en parte de la conducta de los humanos. Las palabras del extracto transcrito en (27) introducen dos futuros nítidamente distinguidos por las formas prospectivas empleadas: por un lado, el porvenir anunciado, y desencadenado por mik(a'aj) que, iniciándose con el deíctico be'oorita "ahorita", se instala como un periodo; por otro lado, el futuro predicho con biin que se proyecta sobre el referencial de los acontecimientos históricos.

\begin{tabular}{|c|c|c|}
\hline $\begin{array}{ll}\mathrm{Ka} & \text { tun } \\
\mathrm{CONJ} & \text { entonces }\end{array}$ & $\begin{array}{ll}\text { bin } & j \text {-máan } \\
\text { EV } & \text { CP.INTR-andar }\end{array}$ & $\begin{array}{l}\text { Ki'ichkelem } \\
\text { Hermoso }\end{array}$ \\
\hline
\end{tabular}

ka a'al-a ti'-o':

CONJ decir-PAS.PF PREP-3PL

y les dijo:

“Ja'libe' tata-e'ex

que.más.da padre-2PL

'Qué más da, padres

be'oriita libre-e'ex

ahorita libre-2PL

ahora, están libres

$\begin{array}{llll}\text { be'oora } \quad \text { mika('a)j } & \text { yaan-tal } & \text { liibertad } \\ \text { ahora } & \text { IMM } & \text { EXIST-IPF.POSIT } & \text { libertad } \\ \text { ahora, va a haber Libertad } & \end{array}$

$\begin{array}{lll}\text { mika('a)j } & \text { usaar-t-e'ex } & \text { ooro } \\ \text { IMM2A } \quad \text { Usar-TRZER-2PL } & \text { oro } \\ \text { van a usar oro } & \end{array}$

mika('a)j usaar-t-e'ex le o'olki nook'-o'-o'

IMM. $2 \mathrm{~A}$ usar-TRZER-2PL DET suave ropa-3PL-TD

van a usar ropas suaves

mika('a)j-e'ex máan ti yóol lik'

IMM-2PL andar PREP sobre aire

van a viajar en el aire

mika('a)j-e'ex jaan-t-e'ex ma'alo' jan-(a)l-o'

iMM-2PL comer-TRZER-2PL bueno comer-IMPF.INTR-TD

van a comer ricas comidas 


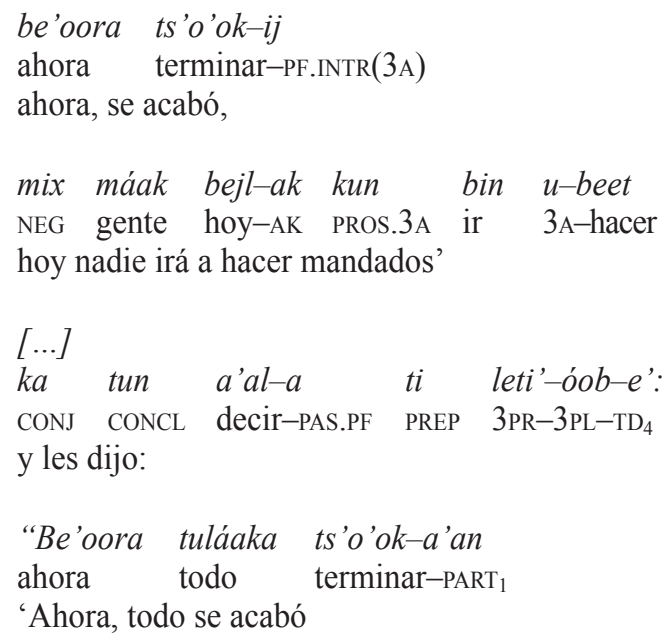
bíin wa úuch-uk tuka'aten-e' fut HYP ocurrir-SBJ.INTR de.nuevo-TD 4
[un día] quizás sucederá de nuevo,

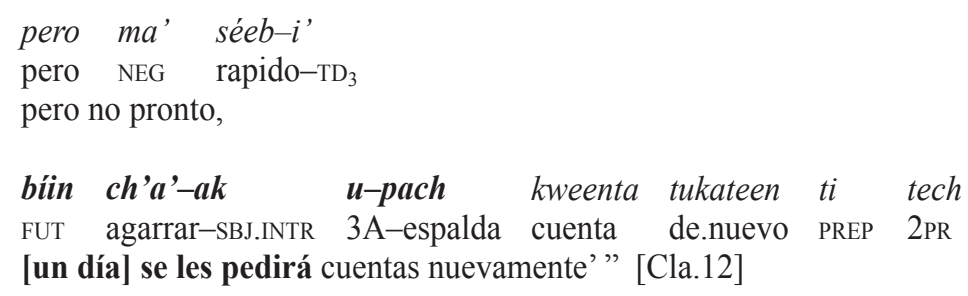

Mik( $\left.a^{\prime} a j\right)$ se usa tanto por su valor aspectual de inminencia como por sus valores más modales y práxicos, anunciadores y resolutivos. Se confirma con el ejemplo siguiente (28). El narrador reproduce aquí también las palabras de Ki'ichkelem Yuum. El prospectivo mik(a'aj) se ve asociado en este caso con la primera persona, que dado las acciones referidas, sólo puede expresar una fuerte autoridad: las palabras con mik(a'aj) provocan el inicio del periodo de Libertad. Lo confirma el comentario conclusivo del locutor, donde explicita el lazo entre las palabras de la divinidad y la instauración de la nueva época histórica.

(28) Pos in-yajma ch'ibal-éex,
CONJ 1A-amado lineaje-2PL
"Bueno, mis queridos descendientes 
Futuros en contrapunto: proyección, predicción y deseo en maya yucateco

pwes be'oritasa $m a$
CONJ ahorita
pues ahorita, no

te'ex-e', ts'ok-a'an tun ti te'ex-i'

2PL.PR-TD ${ }_{4}$ terminar-PART 1 CONJ PREP 2PL.PR-TD

ustedes, ya se terminó para ustedes

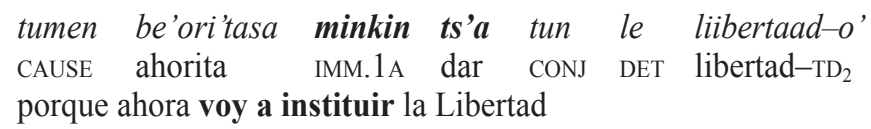

Entoonses tun lel-o' gobyeerno tun kun-maandar ma' te'ex-e'!" entonces CONJ DET-TD 2 gobierno CONJ PROS.3A-mandar NEG 2PL.PR-TD 4 Entonces pues, es el gobierno que mandará, ¡no son ustedes!

Pos bey úuch-ik u-yaan-ta tun le tun le liibertaad-o'. CONJ así ocurrir-MAF 3a-exist-INTR.POSIT CONJ DET CONJ DET libertad-TD 2 Pues así es que hubo pues la, pues la Libertad." [VVA0171-Tin-1-1995]

Además de $\operatorname{mik}\left(a^{\prime} a j\right)$, el proyectivo-deóntico yan también puede servir para la aserción de lo que advendrá en el futuro colectivo de los mayas o de la humanidad actual, un futuro ligado al esquema referencial de predeterminación característico de bín. Yan se usa a menudo para comentar las profecías, sean o no enunciadas en paralelo con bíin. Dicho uso se asemeja a aquellos del tipo guión de yan, pero un guión proyectado aquí a una escala temporal mayor y sobre el plano (o referencial) de los acontecimientos históricos. En (29), un hombre comenta sobre el futuro predicho.

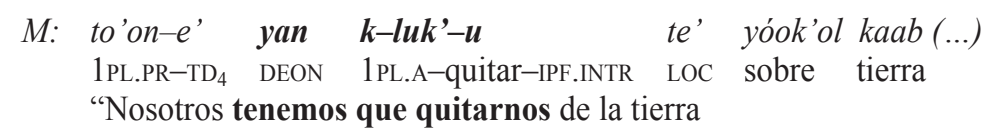

$V$ : pero lel-o' laayli te' yóok'ol kaab kun-'úuch-u pero DET-TD aun LOC sobre tierra PROs.3A-suceder-IPF.INTR ¿Pero va a suceder aquí mismo sobre la tierra?

M: laayli way te' yóok'ol kaab, mismo te' yóok'ol kaab, aun aquí LOC sobre tierra mismo LOC sobre tierra Aquí mismo sobre la tierra, si, sobre la tierra mismo,

ma' un-kaambyar jebix-il-i-e',

NEG 3A.PROG-cambiar como-NOM-PT- $\mathrm{TD}_{4}$ no cambia de todos modos 


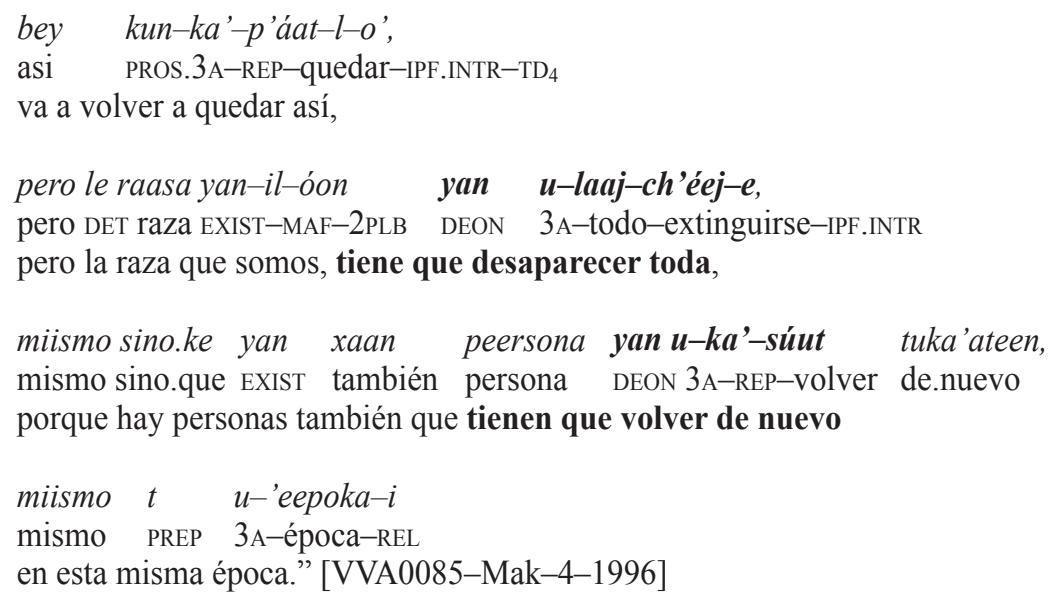

Es significativo que fuera de comentarios como (29) donde el hablante asume su propia voz, yan se use muy escasamente en las palabras proféticas atribuidas a Juan de la Cruz o Ki'ichkelem Yuum. Al menos dos razones pueden motivar tal restricción: en primer lugar, la existencia misma de biin, especializado para dicho contexto y ampliamente privilegiado; en segundo lugar, como lo revela el ejemplo siguiente -ilustrativos de los escasísimos enunciados proféticos en discurso directo con yan de nuestro corpus-, el hecho de que yan aparezca claramente para indicar una relación causal, confirmando por contraste que el tipo de determinación implicada por bín es de naturaleza diferente.

El primer ejemplo (30) recuerda el discurso de Ki'ichkelem Yuum cuando decidió instaurar un nuevo periodo de paz, que dejaría el pueblo santo Saanta Kruus Balamnaj K'ampok'olche en manos de las fuerzas mexicanas; el segundo (31), cita las palabras enunciadas por Jajal Dyos "Verdadero Dios" mediante los saantos, cruces hablantes llevadas por un explorador que antecedía a los soldados durante las batallas de la guerra de Castas.

(30) Bik taake'ex ka xíke'ex tu taanchumuk kaaji'Saanta Kruus Balamnaj K'ampok'olche' "No vayan a ir en el medio de la ciudad de Saanta Kruus Balamnah K'ampok'olche'

tumen awoojlae'ki bin,

porque, saben, dicen que dijo,

kapeekche'tke'ex be'oora'e ki bin,

si ahora lo pisan, dicen que dijo,

de por siile' ki bin

de por sí, dicen que dijo, 
Futuros en contrapunto: proyección, predicción y deseo en maya yucateco

le justisya ken ints'a sino ke'te'ex kene'ex k'ame'ki bin

la justicia que haré, ustedes la recibirán, dicen que dijo

'uuna ma' peekche the'ex insiisaj pixanile'ex

si no lo pisan, mis almas engendradas,

teen a'ik te'ex sino ke'u'uye'ex inkoonsejose' ki bin

yo se los digo, sino que oigan mi consejo, dicen que dijo,

$\begin{array}{llllll}\text { biin } & \text { inw-áant-e'ex } & \text { tulaakal } & \boldsymbol{u} \text {-'oora-i } & k i & \text { bin } \\ \text { FUT } & \text { 1A-ayudar-2PL.B } & \text { todo } & \text { 3A-momento-REL } & \text { CIT } & \text { EV }\end{array}$

les ayudaré, en toda ocasión, dicen que dijo,

tinwéetel yane'ex tulakal u'oorai' ki bin,

estarán conmigo en toda ocasión, dicen que dijo,

pero 'uuna bes ma'awuyke'ex inkoonsejose' ki' bin

pero si no oyen mi consejo, dicen que dijo,

pos ma'alo' de por si te'exe' yan awuyike'exe ba'ax ken úuchu te'ex ki bin.

pues bien, de por sí ustedes tendrán que oir lo que les sucederá dicen que dijo."

[VVA0091-Mak-14-1996]

(31) pero yan diyas tun bin le chen uya'a tun bin kyum jajal dyoose'

"pero había días pues, dicen, cuando se oía a nuestro padre verdadero dios:

- pos ja'alibe' insíisaj pixáani máasewaaliléex,

pues ni modos, mis almas engendradas macehuales

ken t'anak tuka'ateen tuláak' diya beyo',

cuando hablaba de nuevo otro día así:

- chen de por demas ka'xíkéex ki bin

en balde irían, dicen que dijo

deesde be'oora tunmaarkartike'ki bin

a partir de ahora se está marcando dicen que dijo

sino-kee jum-p'e saarjento' wa jum-p'e tenyeente wa jum-p'e kooroneel sino.ke un- $\mathrm{NC}$ sargento $\mathrm{o}$ un- $\mathrm{NC}$ teniente $\mathrm{O}$ un- $\mathrm{NC}$ coronel que un sargento, o un teniente o un coronel

yan u-p'áata de mweerto'e'.

DEON $3 \mathrm{~A}$-quedar de muerto-TD

ha de quedar muerto." [VVA0091-Mak-14-1996] 
En suma, yan y bíin implican ambos cierta necesidad de realización, pero de orden muy distinto. Para yan, ésta depende de un deber moral, de una resolución o de un encadenamiento causal; en cambio en el caso de bíin, se trata de una necesidad ligada a una predeterminación y/o a un acto de palabra profético. Además, mientras que bíin impone un tipo de referencial sobre el cual debe proyectarse el futuro enunciado, yan es neutro en cuanto a referencial.

\section{Las texturas del tiempo}

Al elucidar la variedad de formas posibles para la expresión del futuro y la variedad de uso de cada una, nuestra intención fue no sólo poner en evidencia dicha pluralidad sino, más allá, destacar que las formas prospectivas superan ampliamente la esfera de lo temporal en el sentido estricto o habitual de sucesión antes-después, de localización sobre un calendario, o de distancia métrica temporal. Los valores se extienden a parámetros aspecto-temporales, agentivos, epistémicos y aléticos, dialógicos e intersubjetivos, interaccionales. Estos son esenciales en la definición y el uso de dichas formas y en las formas de aprensión del futuro que componen. Los retomamos brevemente a modo de conclusión.

En términos estrictamente temporales, sólo biin se distingue claramente de los demás marcadores puesto que implica una posterioridad con respecto al tiempo de la enunciación -es un "verdadero" futuro-, así como una indeterminación calendaria. El proximativo ta'ayt implica una proximidad temporal, pero con un hiato entre el tiempo de referencia y el proceso proyectado, a diferencia de $m i k\left(a^{\prime} a j\right)$.

En términos aspectuales, biin muestra un acontecimiento en su globalidad (es su valor aorístico), tal como lo hacen el proyectivo-deóntico yan y el asertivo je'el. En cambio, el inminente mik(a'aj) y el desiderativo tak implican la visualización interna de un proceso en desarrollo: $m i k\left(a{ }^{\prime} a j\right)$ focaliza la fase inmediatamente anterior a la acción; tak da a ver un despliegue télico, aquel de una fuerza irreprensible que conduce a la acción.

En términos agentivos, mientras bíin indexa una separación de la esfera de control de los interlocutores -humanos-, mik( $a^{\prime}$ aj) y yan se usan a menudo en expresiones que implican intencionalidad y control, aún si dichos valores no están estrictamente hablando codificados por las formas, y en ciertos casos yan sella un compromiso fuerte. Tak por lo contrario, implica una ausencia de control, como bíin pero cuya causa difiere en absoluto, en un modo casi inverso. Mientras que para bíin la ausencia de control resulta de que los acontecimientos estén situados en un plano factual fuera del alcance directo de los humanos, en el caso de tak, la ausencia de control resulta de una fuerza interna irreprensible.

En términos epistémicos y aléticos, je'el es asertivo, marca el ámbito de lo cierto, seguro o asegurado, las otras formas son neutras en cuanto a dicho valor 
Futuros en contrapunto: proyección, predicción y deseo en maya yucateco
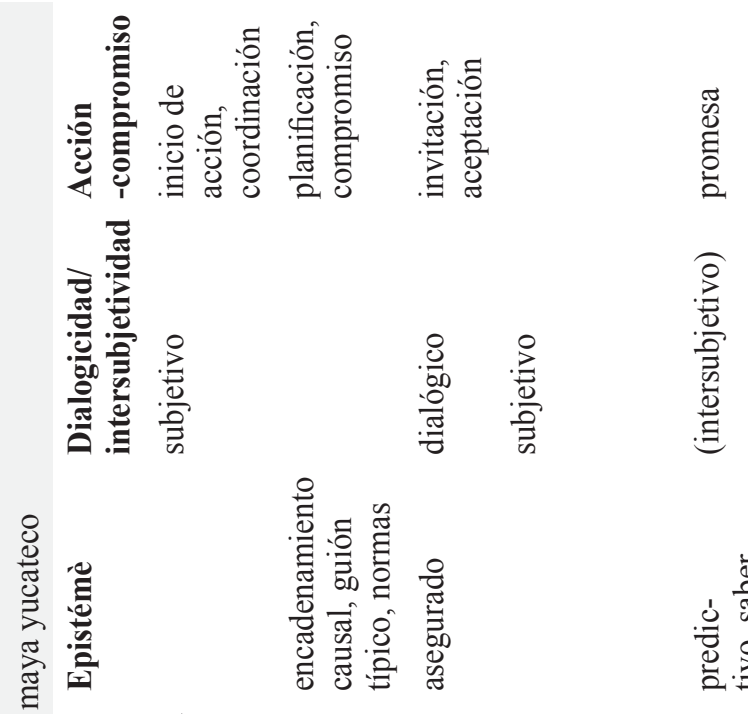

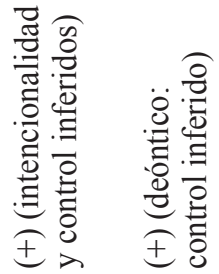
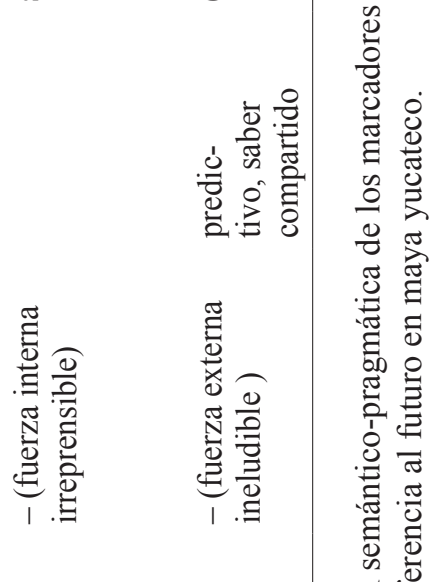

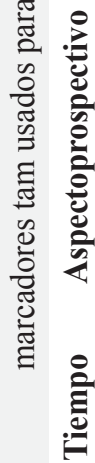

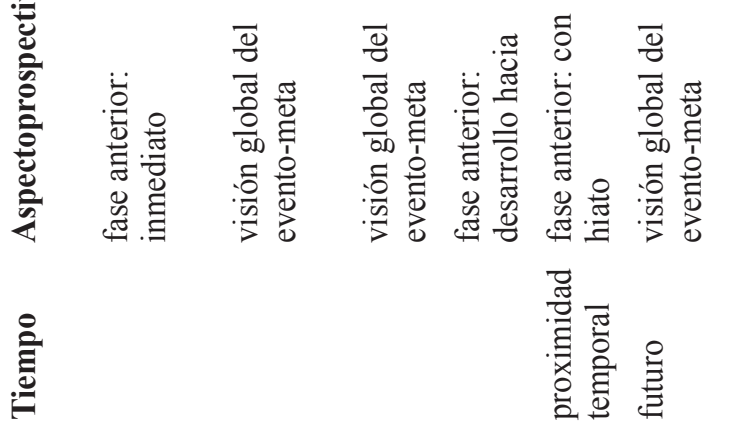

. 도

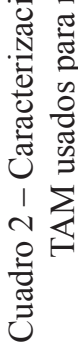

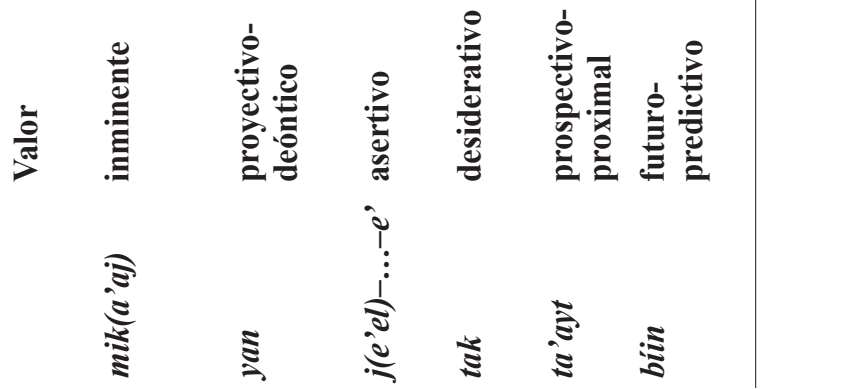


pero se integran a esferas de saber distintas, como se precisa más abajo. En el caso de mik( $\left.a^{\prime} a j\right)$, sin embargo, nos encontramos en un grado de iniciación de la acción tal que ésta ya existe necesariamente (de modo que la acción referida aparece como de realización necesaria y segura, aunque dicha necesidad y dicha seguridad sean valores inferidos). Yan sirve para expresar una relación causal entre dos acontecimientos, pero como también sirve de manera más general para encadenamientos práxicos esperados, incluyendo guiones típicos de acción, se trata de una necesidad débil. No hemos hablado aquí de la necesidad fuerte, que expresan en maya $k^{\prime}$ 'abeet y $k^{\prime}$ ana'an.

En términos dialógicos e intersubjectivos, biin remite más que todo a un saber simétrico en sus usos polifónicos más comunes. Aunque los enunciados con bíin puedan recibir marcas modales de incertidumbre por ejemplo, no implican una confrontación de puntos de vista como lo hace je'el, sino que se basan en un saber compartido. Je' el es fundamentalmente dialógico, en cuanto al marco participativo de la enunciación, y en términos más bakhtinianos de intertextualidad. Implica tanto una pluralidad de vías posibles de porvenir como una confrontación de puntos de vista con la selección asertiva de una o uno de ellos. Mik ( $\left.a^{\prime}{ }^{\prime} j\right)$ y tak están, por lo contrario, íntimamente atados a la subjetividad del sujeto de la proposición, ya sea por el carácter emergente de una acción in situ, ya sea por el tipo de sensación interna expresada. Ambos son experiencialmente asimétricos, lo que confirman la predominancia de los usos con primera persona, la ausencia o rareza de usos de $m i k\left(a^{\prime}{ }^{\prime}{ }^{\prime}\right)$ en preguntas, y su asociación con deícticos de inmediatez, en particular aquellos con el clítico proximal/asimétrico $a^{\prime}$ (véase Hanks 1990, 2005 para un análisis de $a^{\prime}$ ).

En términos de acciones y compromisos, $m i k\left(a^{\prime} a j\right)$ actúa en la coordinación de las acciones in situ, yan en cierta medida también en el caso de las indicaciones instrumentales, pero yan sirve además para la planificación, la decisión meditada, el compromiso ritual. Je el...-e’ permite incluir al otro en una acción proyectada y aceptar participar, en el marco de una variedad de actividades, sean éstas cotidianas, políticas o rituales. Bíin puede ser desviado para expresar un compromiso personal: al situar una acción proyectada como perteneciente al ámbito de la predeterminación, se asegura su realización (pues se la sitúa fuera de la inconstancia humana).

Esta presentación analítica de las formas prospectivas en maya yucateco permitió poner de relieve la textura compuesta de lo que consideramos temporalidad. Es importante recalcar que los parámetros mencionados se encuentran, con el mismo carácter inextricable, a través de las lenguas (véase Tournadre 2016, por ejemplo) como es importante recalcar, a la vez, las formas precisas que su expresión toma en maya. El maya yucateco ha gramaticalizado un número notable de formas prospectivas. Su estudio confirma la importancia de los parámetros subjetivo/no subjetivo (e intersubjetivo por inferencia) y saber simétrico/ asimétrico en el campo de la anticipación, y revela la gramaticalización de la 
predeterminación así como la del no control más que del control, por fin la ausencia de codificación de la intencionalidad, aun si existen usos típicos de ciertas formas para expresarla.

Por último queremos insistir en el interés de observar cómo estos modos de presentar el porvenir se inscriben en y moldean diferentes actos de palabras géneros discursivos y contextos de lo vivido. En el ámbito de las actividades diarias, notamos el papel de yan para expresar -y así formar-planes, instrucciones, recomendaciones, y recordar guiones típicos de acción, el "cómo ha de hacerse"; la importancia de mik ( $\left.a^{\prime} a j\right)$ para los anuncios y la coordinación; el uso ineludible de je 'el... e' para la invitación a participar, la aserción y selección en caso de duda, la amonestación (que permite orientar el futuro); y se notó, en todos esos contextos, la exclusión del predictivo bín. Del lado opuesto, en el plano del devenir colectivo, el del futuro histórico y de las profecías, resalta la especialización de bín para la predicción y la predeterminación, el uso de yan para explicitar las relaciones causales entre eventos, y de mik( $\left.a^{\prime} a j\right)$ para la actualización de un acontecimiento, la instauración de un periodo o una etapa por voz autorizada. Notaremos también la ausencia del asertivo je 'el...e ' para la referencia al futuro histórico, como si, al fin de cuentas mayas, los humanos no podrían en ese ámbito, y a pesar de su vínculo con el pasado, atreverse a asegurar nada.

Observamos algunos procesos de gramaticalización, que ofrecen una nueva declinación de procesos diacrónicos listados a través de las lenguas. El proyectivo-deóntico yan tiene su origen en una forma existencial, el desiderativo no intencional tak se ha ligeramente extendido a ciertas acciones controlables, y dos formas tienen origen en el verbo "ir". Aunque la gramaticalización de un verbo "ir" para formar futuros o prospectivos es muy común en lenguas de orígenes diversos, es notable que el maya yucateco haya desarrollado dos formas casi opuestas de pensar el futuro a partir de ese mismo verbo. Mientras mik $\left(a^{\prime} a j\right)$ está íntimamente atado a ámbitos del hacer y tomar consciencia en el hic et nunc de la enunciación, bíin refiere a un ámbito del saber que transciende el vivir individual y un ámbito de la experiencia que transciende las capacidades agentivas del hablante común. Las dos gramaticalizaciones de bin "ir" se revelan así como los parangones de dos modos de relacionarse con los eventos que los sistemas gramaticales de las lenguas suelen distinguir moderadamente, pero que el maya yucateco ha llegado a contrastar de manera particularmente sobresaliente, vinculándolos a modos socio-culturales específicos de aprehensión del devenir, un futuro de fabricación y un futuro de memoración.

En horizontes lejanos, el rey de Calvino, solitario en lo profundo de su castillo, perdido en sus pensares, recordaba un tiempo de rey, y tiempos de hombre. Al acecho de voces del pasado, recuerda futuros predichos y aquellos planeados o imaginados, futuros presentes de anhelos y temores. Como en la mente del soberano, aun si en cierto plano del porvenir y del devenir, el futuro maya mira 
hacia el pasado: en el flujo del decir y del vivir se desvelan sus manifestaciones polimorfas, encaminadas por siglos de sedimentación de infinitos minutos de diálogos. Y contemplando palabras y silencios, nuestra comprensión de éstas aún queda ampliamente por venir.*

* Manuscrit reçu en novembre 2015, accepté en mars 2016.

Este artículo forma parte del número especial Compases y texturas del tiempo entre los mayas: lo dicho, lo escrito, lo vivido.

\section{Abreviaciones}

1: primera persona, 2: secunda persona, 3: tercera persona, A: marcadores de persona del juego A (ergativo, sujeto de verbo transitivo, posesor de nominales), ABS: absolutivo, AGP: prefijo de agente $j-$, AK: sufijo de referencia temporal cumplida, AP: antipasivo, Ass: asertivo; B: marcadores de persona del juego B (absolutivo, sujeto de verbos intransitivos, de predicados no verbales, objeto de verbos transitivos), CAUS: causativo, CICL: cíclico, CIT: ctativo; CONCL: partícula conclusiva, CONF: partícula confirmativa, CONJ: conjunción, CP: completivo, CP.INTR: marcador TAM inicial de completivo intransitivo, CP.TR: marcador TAM inicial de completivo transitivo, CTRFACT: contrafactual ( $k a$ 'achij); DEM: demostrativo, DEON: deóntico, DET: determinante, ENF: enfático, ERG: ergativo, EV: evidencial (reportativo), FUT: futuro, H.RTR: retrospectivo hodiernal, INCH: incoativo, ICP: incompletivo, ICP.INTR: incompletivo intransitivo, IMP: imperativo, INTR: intransitivo, INTRZER: intransitivizador, IPF: imperfectivo, MAF: enfoque de manera, NC: clasificador numeral, NEG: negación, PART: participio, PART1: participio - a'an; PART2: participe pasivo en -bil, РART3: participio mediopasivo -vl/-al; PART4: participio posicional -vkbal, PAS: pasivo, PF: perfectivo, PFT: perfecto, PL: plural, POSIT: posicional, PR: pronombre independiente, PREP: preposición, PROG: progresivo, PROS: prospectivo, PT: partitive, QUANT: cuantificador, REFL: reflexive, REIT: reiterativo, REP: repetitivo, RTR: retrospectivo, R.RTR: retrospectivo remoto, SBJ: subjuntivo, TD: deíctico terminal, $\mathrm{TD}_{1}$ : deíctico terminal (proximal/ información nueva), $\mathrm{TD}_{2}$ : deíctico terminal (distal/saber compartido), $\mathrm{TD}_{3}$ : deíctico terminal (locativo/negación), $\mathrm{TD}_{4}$ : deíctico terminal (tópico), TERM: terminativo, TR: transitivo, TRZER: transitivizador, UNPOS: uso absoluto, no poseído.

\section{Referencias citadas}

Benveniste Emile

1966 Problèmes de linguistique générale I, II, Gallimard, Paris.

Bergeret Agnès

2012 La quête d'autonomie des paysans mayas-q'eqchi' de Cahabón (Guatemala), 1944-2011. Trois perspectives sur les conflits de terre et les politiques de 
Futuros en contrapunto: proyección, predicción y deseo en maya yucateco

développement agricole, thèse d'anthropologie, IHEAL -Université Paris 3 - Sorbonne Nouvelle.

2017 "Narrativas del conflicto y construcciones del pasado entre los q'eqchi'es: del relato de vida al mito", Journal de la Société des américanistes, número especial, (“Compases y texturas del tiempo maya") [en línea]), 2017.

Bender Andrea, Sieghard Beller y Giovanni Bennardo

2010 "Temporal Frames of Reference: Conceptual Analysis and Empirical Evidence from German, English, Mandarin Chinese and Tongan”, Journal of Cognition and Culture, 10, p. 283-307.

BERGQVist Henrik

2008 Temporal Reference in Lakandon Maya: Speaker and Event Perspectives, Ph.D. dissertation, School of Oriental and African Studies, Endangered Languages Academic Programme, University of London.

2017 "Time and commitment: the grammaticalization of uúch in Lakandon Maya", Journal de la Société des américanistes, special issue, ("Measures and textures of time among the Mayas" [on-line]), 2017.

BOHNEMEYER Jürgen

1998 Time Relations in Discourse: Evidence from a Comparative Approach to Yukatek Maya, Ph.D., doctoral dissertation, Katholieke Universteit Brabant.

2002 The Grammar of Time Reference in Yukatek Maya, Lincom Europa, Munich.

2010 "Temporal Anaphora in a Tenseless Language", in Wolfgang Klein and Ping Li (eds), The Expression of Time, Mouton de Gruyter, Amsterdam, p. 83-128.

BORODITSKY Lera

2000 "Metaphoric Structuring: Understanding Time through Spatial Metaphors", Cognition, 75, p. 1-28.

Botne Robert y Tiffany L. Kershner

2008 "Tense and Cognitive Space: On the Organization of Tense/Aspect Systems in Bantu Languages and beyond", Cognitive Linguistics, 19 (2), p. 145-218.

BRICEÑo Chel Fidencio

1997 De gramaticalización y degramaticalización: Dos procesos en el maya yucateco actual, tesis de maestría en lingüística, Escuela Nacional de Antropología e Historia, México (D.F.).

BRICKER Victoria R.

1981a The Indian Christ, the Indian King: the Historical Substrate of Maya Myth and Ritual, University of Texas Press, Austin.

1981b “Grammatical Introduction”, in Eleuterio. Po'ot Yah, Yucatec Maya Verbs (Hocaba Dialect), Center for Latin American Studies, Tulane University, New Orleans, L.A., p. v-xlviii.

Brown Penelope

2012 “Time and Space in Tzeltal: is the Future Uphill?", Frontiers in psychology [on-line], 3, https://doi.org/10.3389/fpsyg.2012.00212

CALvino Italo

[ms circa 1979] Un re in ascolto. Libreto de la ópera de Luciano Berio, Un re in ascolto (1979-1984). 
DAHL Östen

2000 "The Grammar of Future Time Reference in European Languages", in Östen Dahl (ed.), Tense and Aspects in the Languages of Europe, Berlin/New York, Mouton de Gruyter, p. 309-328.

De la Garza Mercedes

1975 La conciencia histórica de los antiguos mayas, Universidad Nacional Autónoma de México, Centro de Estudios Mayas (Serie Cuadernos, 11), México.

De León PAsquel Lourdes

2005 La llegada del alma. Lenguaje, infancia y socialización entre los mayas de Zinacatán. Centro de Investigaciones y Estudios Superiores en Antropología Social, Instituto Nacional de Antropología e Historia, México.

Desclés Jean-Pierre

2002 "Categorization: A Logical Approach to a Cognitive Problem”, Journal of Cognitive Science, 3 (2), p. 85-137.

Desclés Jean-Pierre y Zltaka Guentchéva

2011 "Référentiels aspecto-temporels : une approche formelle et cognitive appliquée au français", Bulletin de la Société de linguistique de Paris, 106 (1), p. 95-127.

2012 "Universals and Typology", in Robert I. Binnick (ed.), The Oxford Handbook of Tense and Aspect, Oxford University Press, Oxford/New York, p. 123-154.

DuMOND Don E.

2005 [1997] El machete y la cruz. La sublevación de los campesinos en Yucatán, UNAM, Plumsock Mesoamerican Studies, Mayan Educational Foundation.

EDMONSON Munro S.

1982 The Ancient Future of the Itzas: the Book of Chilam Balam of Tizimin, (trad. et notes de M.S. Edmonson), University of Texas Press, Austin.

ENFIELD Nick J.

2002 Ethnosyntax: Explorations in Grammar and Culture, Oxford University Press, Oxford.

Evans Vyvyan

2013 “Temporal Frames of Reference”, Cognitive Linguistics, 24 (3), p. 393-435.

FARRISS Nancy

1987 "Remembering the Future, Anticipating the Past: History, Time and Cosmology among the Maya of Yucatán", Comparative Studies in Society and History, 29 , p. 566-593.

Fleischman Suzanne

1982 The future in Thought and Language. Diachronic Evidence from Romance. Cambridge University Press, Cambridge.

1983 "From pragmatics to grammar: Diachronic reflexions on the development of complex pasts and futures in Romance". Lingua, 60, p. 183-214.

GaSkINS Suzanne

2000 “Children's Daily Activities in a Mayan Village: A Culturally Grounded Description”, Journal of cross-cultural research, 34 (4), p. 375-389. 
Futuros en contrapunto: proyección, predicción y deseo en maya yucateco

Gossen Gary

1974 Chamulas in the World of the Sun: Time and Space in a Maya Oral Tradition. Harvard University Press, Cambridge M.A.

1999 Telling Maya Tales. Tzotzil Identities in Modern Mexico, Routlegde, New York and London.

Hanks William

1990 Referential Practice: Language and Lived Space among the Maya, University of Chicago Press, Chicago, London.

2005 "Explorations in the Deictic Field", Current Anthropology, 46 (2), p. 191-220. HeIne Bernd, Ulrike Claudi y Friederike Hünnemeyer

1991 Grammaticalization: A Conceptual Framework, Chicago University Press, Chicago.

Heine Bernd y Tania Kuteva

2002 World Lexicon of Grammaticalization, Cambridge University Press, Cambridge.

Kockelman Paul

2004 "Stance and Subjectivity", Journal of Linguistic Anthropology, 14, p. 127-150.

2010 Language, Culture and Mind. Natural Constructions of Social Kinds, Cambridge University Press, Cambridge.

Le Guen Olivier

2012 "Exploration in the Domain of Time: from Yucatec Maya Time Gestures to Yucatec Maya Sign Language Time Signs", in Ulrike Zeshan and Connie De Vos (eds) Endangered Sign Languages in Village Communities: Anthropological and Linguisitic Insights, Mouton de Gruyter \& Ishara Press, Berlin, p. 209-250.

2017 "Una concepción del tiempo no-lineal en dos lenguas: el maya yucateco colonial y actual y la lengua de señas maya yucateca", Journal de la Société des américanistes, número especial, ("Compases y texturas del tiempo maya" [en línea]), 2017.

Le Guen Olivier y Lorena Pool Balam

2012 "No Metaphorical Timeline in Gesture and Cognition among Yucatec Mayas", Frontiers in cultural Psychology [on-line], vol. 3, https://doi.org/10.3389/ fpsyg.2012.00271

Levinson Stephen C.

2003 Space in Language and Cognition, Cambridge University Press, Cambridge. LoIs Ximena y Valentina VAPNARSKY

2003 Polyvalence of Root Classes in Yukatekan Mayan Languages, Lincom Europa, Münich.

Metz Brent E.

2006 Ch'orti'-Maya Survival in Eastern Guatemala. Indigeneity in Transition, University of New Mexico Press, Albuquerque.

Mithun Marianne

1984 “The Evolution of Noun Incorporation”, Language, 60, p. 847-895. 
Monod BecQuelin Aurore

1995 “Mayas. Avenir, futur et négation. Notes sur l'usage tzeltal”, Trace, 28, Centre français d'études mexicaines et centraméricaines, México, p. 71-88.

2012 « La frontière épaisse. Introduction », Ateliers d'anthropologie [en ligne], 37, http://ateliers.revues.org/9170, https://doi.org/10.4000/ateliers.9170, consultado el 23/11/2015.

Novakova Iva

2001 Sémantique du futur : étude comparée français-bulgare, L'Harmattan, Paris.

NúÑEZ R. E. y E. SWEETSER

2006 "With the Future behind Them: Convergent Evidence from Aymara Language and Gesture in the Crosslinguistic Comparison of Spatial Construals of Time", Cognitive Science, 30 (3), p. 401-450.

Окоsнi Tsubasa

2015 “Construcción del 'futuro pasado': una reflexión sobre la elaboración y traslado de los títulos de tierras mayas coloniales", comunicación en el coloquio El maya: variación y reflexión lingüística ante la estandarización, noviembre 3-5, 2015, CEPHCIS, UNAM, Mérida.

Schumann G. Otto

1981 "La relación lingüística chuj-tojolabal”, in Mario Humberto Ruz (ed.), Los legítimos hombres: aproximación antropológica al grupo tojolabal, Centro de Estudios Mayas, Instituto de Investigaciones Filológicas, Universidad Nacional Autónoma de México, México, vol. I, p. 129-169.

SMAiLus Ortwin

1989 Gramática del Maya Yucateco Colonial, Wayasbah, Verlag, Hamburg.

Sullivan Paul

1983 Contemporary Yucatec Maya Apocalyptic Prophecy: The Ethnographic and Historical Context, Ph.D., John Hopkins, University. Baltimore.

TENBRICK Thora

2011 "Reference Frames of Space and Time in Language", Journal of Pragmatics, 43, p. 704-722.

TOURNADRE Nicolas

2016 "The Future Tenses in the Tibetic Languages", in Zlatka Guentchéva (ed.), Aspectuality and Temporality: Theoretical and Empirical Issues, John Benjamins, p. 625-641.

VAPNARSKY Valentina

1996 "The Voice of Prophecies: Expressions and Visions of Time in Yucatec Maya", in Ueli Hostettler (ed.), Los Mayas de Quintana Roo, Institut für Ethnologie der Universität Bern, Arbeitsblätter, nº 14, Bern, p. 13-39.

1999 Expressions et conceptions du temps chez les Mayas yucatèques, thèse de doctorat, Université Paris 10, Nanterre.

2009 "Predicción y performatividad en la memoria histórica maya yucateca", in Antje Gunsenheimer, Tsubasa Okoshi Harada y John Chuchiak (eds), Texto y contexto: Perspectivas intraculturales en el análisis de la literatura maya yucateca, BAS, Bonn, p. 257-288. 
Futuros en contrapunto: proyección, predicción y deseo en maya yucateco

2013a «Le passif peut-il éclairer les esprits? Agentivités, interactions et esprits-maîtres chez les Mayas », Ateliers d'Anthropologie [en ligne], 39 (2), http:// ateliers.revues.org/9449

2013 b "Mandatos y solicitudes: el arte cotidiano del pedir en maya yucateco", in Philippe Nondédéo and Alain Breton (eds), Maya Daily Lives, Verlag Anton Saurwein, Mark Schwaben, Germany, p. 169-183.

2016 "No Escape from the Future. Temporal Frames and Prediction in Yucatec Maya”, in Zlatka Guentchéva (ed.), Aspectuality and Temporality: Theoretical and Empirical Issues, John Benjamins, p. 643-678.

2018 "Inference crisscross: Disentangling evidence, stance and (inter)subjectivity", in Zlatka Guentchéva (ed). Epistemic modality, evidentiality, (inter)subjectivity: cross-linguistic approaches. Mouton de Gruyter, Berlin.

Vet Co

1993 "Conditions d'emploi et interprétation des temps futurs du français", Verbum, 16, p. 71-84.

Villa Rojas Alfonso

1978 Los elegidos de Dios. Etnografía de los mayas de Quintana Roo, Instituto Nacional Indigenista, Serie de Antropología Social, 56, México. 
